\title{
Stability Analysis of Cutting Process with Internally Damped Rotating Tapered Composite Cutter Bar
}

\author{
Yuhuan Zhang $(\mathbb{D}$, Yongsheng Ren $(\mathbb{D}$, and Jinfeng Zhang \\ College of Mechanical and Electronic Engineering, Shandong University of Science and Technology, Qingdao 266590, China \\ Correspondence should be addressed to Yongsheng Ren; renys@sdust.edu.cn
}

Received 25 April 2020; Revised 7 June 2020; Accepted 16 June 2020; Published 1 August 2020

Academic Editor: Marek Lefik

Copyright ( 92020 Yuhuan Zhang et al. This is an open access article distributed under the Creative Commons Attribution License, which permits unrestricted use, distribution, and reproduction in any medium, provided the original work is properly cited.

\begin{abstract}
Using the cutter bar made with composite rather than metal in high rotating speed milling or boring operations is a new attempt for suppressing chatter of the cutting system. This is because composite material has much higher specific stiffness and damping as well as dynamic stiffness compared to metal. But, for a rotating composite cutter bar, larger internal damping (or rotational damping) occurs, and such damping may cause the rotor instability in the perspective of rotor dynamics. On the other hand, the effect of internal damping of a rotating composite cutter bar on the chatter stability in high speed cutting process is also an important issue worthy of concern. In this paper, a new dynamic model of the cutting system with a rotating composite cutter bar is presented. The cutter bar is modelled as a rotating, cantilever, tapered, composite Euler-Bernoulli shaft, subjected to a regenerative cutting force. Modal damping loss factors are described based on the viscoelastic constitutive relation of composite combined with an energy approach. The governing equations of the system are obtained by employing Hamilton principle. Galerkin method is used to discretize the partial differential equations of motion. The frequency-domain solution of stability proposed by Altintas and Budak [14] is extended and used to predict the chatter stability of the cutting system. The results reveal the inherent relationship between internal damping instability and cutting chatter. The effects of the geometry parameters of the cutter bar, ply angle, stacking sequences, and internal and external damping are examined.
\end{abstract}

\section{Introduction}

The cutter bar used in the milling or boring operation is frequently long and slender and thus sensitive to excitation forces introduced by the material deformation process in the machining operations. For example, using conventional steel boring bars in boring process, the chatter usually occurs when the aspect ratio $l / d$ of the boring bars is larger than 5 due to the low dynamic stiffness of steel. Chatter is a type of self-excited vibration, which is mainly caused by the interaction between cutting forces and undulation on the workpiece surface produced by the previous tool passes. Chatter is detrimental for machining precision and machining quality of the surface. Moreover, chatter may cause the decrease of service life of cutting tool and machine tool.

Since the beginning of the 20th century, considerable technique progress for reducing machining vibrations has been made. Chatters can be suppressed by employing either active or passive damping techniques [1]. Although active control is more effective in chatter suppression, it is very expensive, since the active control device is complex in design and consumes high external power. In contrast, passive control device does not need external energy and is easy to implement. In order to increase chatter resistance, boring bar may be equipped with some special passive damping devices [2-5]. However, the special damping devices are not suitable for slender cutting tool used in deep hole boring operations because of installation difficulties. In recent years, the development of advanced composite has provided a novel way to suppress cutting chatter. It is discovered that carbon fiber epoxy composite materials have a much higher specific stiffness and higher damping than conventional cutting tool materials. If composite is employed, the dynamic stiffness and fundamental natural frequency of cutter bar may be improved simultaneously. 
This is very beneficial for the stability of high rotational speed machining for deep holes.

Lee and Suh [6] developed a fixed type graphite/epoxy composite boring bar whose $l / d$ was 5.6 and allowable depth of cut was 5 times higher than that of the conventional steel boring bar. Nagano et al. [7] designed a fixed type carbon fiber/epoxy composite boring bar having different shaped steel cores; its aspect ratio without chatter was 7; and they investigated the effects of steel core shape on the bending stiffness and the natural frequency of carbon fiber epoxy composite boring bars. Yuhuan et al. [8] developed a theoretical analysis model for the prediction of the chatter stability of the composite boring bar with constrained layer damping in order to suppress the chatter of composite boring bar.

But these previous researches on stability analysis for the boring process have focused on boring with stationary composite boring bars and rotating workpieces in which the cutting force directions on the tools in the inertial coordinates are fixed. In fact, employing rotating boring bars and stationary workpieces is also a commonly used way in machining process.

Lee et al. [9] designed and manufactured a rotating composite boring bar. Dynamic optimum design for the composite boring bar was experimentally conducted through vibration tests and cutting process. Kim et al. [10] addressed the forced response and stability of a rotating tapered composite cutter bar subjected to cutting forces. Ma and Ren [11] investigated the free vibration and chatter stability of a rotating thin-walled composite bar under the action of regenerative milling force. Results showed that rotary gyroscopic effects lower the critical depth of cut in high speed milling.

Considering rotating composite cutting tool in cutting process will pose some new questions worthy of exploration. From the perspective of rotor dynamics, effect of internal damping on the dynamic stability of rotating composite shaft is related not only to energy dissipative properties of composite but also to rotating speed of the shaft [12]. Once the rotating speed of a shaft exceeds instability threshold, internal damping destabilizes the whirling motion. Since composite has relatively high-damping characteristics, for a shaft made with composite materials, instability caused by internal damping cannot be ignored.

Internal damping is also called rotating damping to distinguish it from external damping (or called nonrotating damping). As a rotating system, rotating composite cutter bar also has the dynamic instability problem similar to the rotating composite drive shaft induced by internal damping.

In particular, if the rotating speed of composite cutter bar is above the instability threshold, the behavior of chatter stability in the cutting process may be influenced by composite internal damping, and some new chatter unstable phenomenon may occur.

Accurate prediction of internal damping characteristics of composite cutter bar and, on this basis, considering the effect of the internal damping on cutting stability are therefore fundamental for the dynamic design of the machining process with high rotating speed composite cutter bar. However, no work seems to have been reported towards the damping model and analysis for composite cutter bar to date. Also, a few studies involve the effect of the internal damping on cutting stability for rotating composite cutter bar.

Although the influences of gyroscopic effect, taper ratio, and internal damping of composite tool have been considered in $[10,11]$, the internal damping parameter used is given empirically. Ren and Zhang [13] have studied the chatter stability in cutting process with a rotating tapered cutter bar considering internal and external damping, where the cutter bar was made of steel. No studies of damping dissipative mechanism for composite cutter bar have been carried out in the previous literatures. Moreover, the critical rotating speed and instability threshold of rotating composite cutter bar have not been considered, and the relationship between internal damping instability and chatter instability has not been clarified.

In this paper, the cutting dynamic model that employs a rotating tapered composite cutter bar and includes the effect of internal and external damping is developed to predict chatter stability in milling operation. The cutter bar is acted upon by a regenerative cutting force. The damping properties of the cutter bar are described based on viscoelastic constitutive equations of composite and an energy approach. The governing equations of system are obtained by employing Hamilton principle combined with the Euler-Bernoulli theory. Galerkin method is used to discretize the partial differential equations of motion and produce the coupled ordinary differential-delay equations of cutting system. The modal loss factors of cutter bar are predicted by analyzing the free vibration of the nonrotating cutter bar. The critical rotating speed and instability threshold can be further obtained from the eigenvalue analysis for rotating cutter bar. A frequency domain method developed by Altintas and Budak [14] is modified and used here to predict the cutting stability, and the numerical integration validation is also provided. The influence of taper ratio, aspect ratio, ply angle, stacking sequences, and internal and external damping is examined. The results demonstrate significant effects of rotation and internal damping on the stability of cutter bar. At a high rotating speed, new unstable regions are developed, which do not exist in absence of rotation or internal damping. Meanwhile, the results suggest that the starting rotating speed of the new instable region equals to the instability threshold of cutter bar.

\section{Mathematical Model}

2.1. Equations of Motion. Figure 1 shows a rotating tapered composite cutter bar with a rotating speed $\Omega$, and the cross section radius varies linearly with distance $x$ from the fixed end: $R(x)=[1-(1-\sigma) x / l] R_{T}$, where $l$ denotes the bar length, $\sigma=R_{R} / R_{T}$ denotes the taper ratio of the cutter bar, and $R_{T}$ and $R_{R}$ denote the external radius at the fixed and free end, respectively.

The kinetic energy of a rotating tapered composite cutter bar can be expressed as 


$$
T=\frac{1}{2} \int_{0}^{l}\left[m(x)\left(\dot{u}_{y}^{2}+\dot{u}_{z}^{2}\right)+I_{m}(x)\left(\dot{\psi}_{y}^{2}+\dot{\psi}_{z}^{2}\right)-4 \Omega I_{m}(x) \psi_{z} \dot{\psi}_{y}\right] \mathrm{d} x,
$$

where $u_{y}$ and $u_{z}$ denote the displacements of the central line of the cutter bar in $y$ and $z$ directions, respectively. $\psi_{z}$ and $\psi_{y}$ denote the rotations about $y$ - and $z$-axes, respectively. $m(x)$ and $I_{m}(x)$ denote the mass per unit length and the mass moment of inertia, respectively. In these equations, the superposed dots denote derivatives with respect to the time $t$.

For an $M$-layered laminate cutter bar (see Figure 2), the mass per unit length $m(x)$ and the moment of mass inertia $I_{m}(x)$ can be written as [15]

$$
\begin{aligned}
m(x) & =\pi \sum_{k=1}^{M} \rho_{k}\left[r_{k+1}^{2}(x)-r_{k}^{2}(x)\right], \\
I_{m}(x) & =\frac{\pi}{4} \sum_{k=1}^{M} \rho_{k}\left[r_{k+1}^{4}(x)-r_{k}^{4}(x)\right],
\end{aligned}
$$

where $r_{k}(x)$ and $r_{k+1}(x)$ are the internal and external radius of layer $k$ and $\rho_{k}$ is the mass density of layer $k$.

The expression for kinetic energy is

$$
U=\frac{1}{2} \int_{0}^{l}\left[D_{11}(x)\left(\left(\frac{\partial \psi_{y}}{\partial x}\right)^{2}+\left(\frac{\partial \psi_{z}}{\partial x}\right)^{2}\right)\right] \mathrm{d} x
$$

where $I(x)$ denotes the area moment of inertia, and the spatial varying flexural stiffness of the composite cutter bar can be expressed as [15]

$$
D_{11}(x)=\frac{\pi}{4} \sum_{k=1}^{M} \bar{Q}_{11}\left[r_{k+1}^{4}(x)-r_{k}^{4}(x)\right]
$$

where $\bar{Q}_{11}$ is off-axis stiffness. The detailed definitions for $\bar{Q}_{11}$ are given in the Appendix.

The virtual work due to the nonconservative forces can be broken down the virtual work done by the external damping forces and that which is done by the internal damping:

$$
\int_{t_{1}}^{t_{2}} \delta W_{d} \mathrm{~d} t=\int_{t_{1}}^{t_{2}} \delta W_{d}^{I} \mathrm{~d} t+\int_{t_{1}}^{t_{2}} \delta W_{d}^{E} \mathrm{~d} t
$$

Assuming that the cutter bar is subjected to distributed external damping force that is proportional to flexural vibration velocity of the cutter bar and the effect of shear deformation is neglected, the virtual work due to the external damping can be expressed as

$$
\int_{t_{1}}^{t_{2}} \delta W_{d}^{E} \mathrm{~d} t=\int_{0}^{l}\left[\int_{t_{1}}^{t_{2}}\left(-c_{E} \frac{\partial u_{y}}{\partial t}\right) \delta u_{y} \mathrm{~d} t+\int_{t_{1}}^{t_{2}}\left(-c_{E} \frac{\partial u_{z}}{\partial t}\right) \delta u_{z} \mathrm{~d} t\right] \mathrm{d} x
$$

where $C_{E}$ denotes the viscous external damping coefficient.

According to [16], the flexural bending moments of the cutter bar can be written as

$$
\begin{aligned}
& M_{y}=-D_{11}(x) \frac{\partial^{2} u_{z}}{\partial x^{2}}-C_{I} I(x) \frac{\partial^{2} \dot{u}_{z}}{\partial x^{2}}+C_{I} I(x) \Omega \frac{\partial^{2} u_{y}}{\partial x^{2}}, \\
& M_{z}=-D_{11}(x) \frac{\partial^{2} u_{y}}{\partial x^{2}}-C_{I} I(x) \frac{\partial^{2} \dot{u}_{y}}{\partial x^{2}}-C_{I} I(x) \Omega \frac{\partial^{2} u_{z}}{\partial x^{2}},
\end{aligned}
$$

where $C_{\mathrm{I}}$ denotes Kelvin-Voigt internal damping coefficient.

The first term of equation (7) is the conservative moment and it has already been reflected in the potential energy equation, equation (3). The rest of the terms represent the nonconservative moments that are resultant of the internal damping. Thus, the virtual work due to the internal damping can be expressed as

$$
\begin{aligned}
\int_{t_{1}}^{t_{2}} \delta W_{d}^{I} \mathrm{~d} t= & \int_{0}^{l}\left\{\int_{t_{1}}^{t_{2}} \frac{\partial}{\partial x}\left[-c_{I} I(x) \frac{\partial^{2} \dot{u}_{z}}{\partial x^{2}}+c_{I} I(x) \Omega \frac{\partial^{2} u_{y}}{\partial x^{2}}\right] \delta \psi_{y} \mathrm{~d} t\right. \\
& \left.+\int_{t_{1}}^{t_{2}} \frac{\partial}{\partial x}\left[c_{I} I(x) \frac{\partial^{2} \dot{u}_{y}}{\partial x^{2}}+c_{I} I(x) \Omega \frac{\partial^{2} u_{z}}{\partial x^{2}}\right] \delta \psi_{z} \mathrm{~d} t\right\} \mathrm{d} x .
\end{aligned}
$$

The virtual work of the external force can be expressed as

$$
\delta W=\int_{0}^{l}\left(L_{y} \delta u_{y}+L_{z} \delta u_{z}\right) \mathrm{d} x,
$$

where

$$
\begin{aligned}
& L_{y}=F_{y} \delta_{D}(x-l), \\
& L_{z}=F_{z} \delta_{D}(x-l) .
\end{aligned}
$$

where $\delta$ is the variation symbol and $\delta_{D}$ is the Dirac function.

Based on the Bernoulli-Euler beam theory, the rotation angle and the displacement meet the following relations:

$$
\begin{gathered}
\psi_{z}=-\frac{\partial u_{z}}{\partial x}, \\
\psi_{y}=\frac{\partial u_{y}}{\partial x} .
\end{gathered}
$$

In order to derive the equation of motion of the cutting system, the following expression can be used based on the Hamilton principle:

$$
\int_{t_{1}}^{t_{2}} \delta(T-U) \mathrm{d} t+\int_{t_{1}}^{t_{2}} \delta W \mathrm{~d} t+\int_{t_{1}}^{t_{2}} \delta W_{d} \mathrm{~d} t=0
$$

By substituting equations (1), (3), (6), (8), and (9) into equation (12), the bending-bending coupled equations of motion can be obtained as

$$
m(x) \ddot{u}_{y}+C_{E} \dot{u}_{y}-I_{m}(x) \frac{\partial^{2} \ddot{u}_{y}}{\partial x^{2}}-2 I_{m}(x) \Omega \frac{\partial^{2} \dot{u}_{z}}{\partial x^{2}}-\frac{\partial^{2} M_{z}}{\partial x^{2}}=L_{y},
$$

$$
m(x) \ddot{u}_{z}+C_{E} \dot{u}_{z}-I_{m}(x) \frac{\partial^{2} \ddot{u}_{z}}{\partial x^{2}}+2 I_{m}(x) \Omega \frac{\partial^{2} \dot{u}_{y}}{\partial x^{2}}-\frac{\partial^{2} M_{y}}{\partial x^{2}}=L_{z} \text {. }
$$




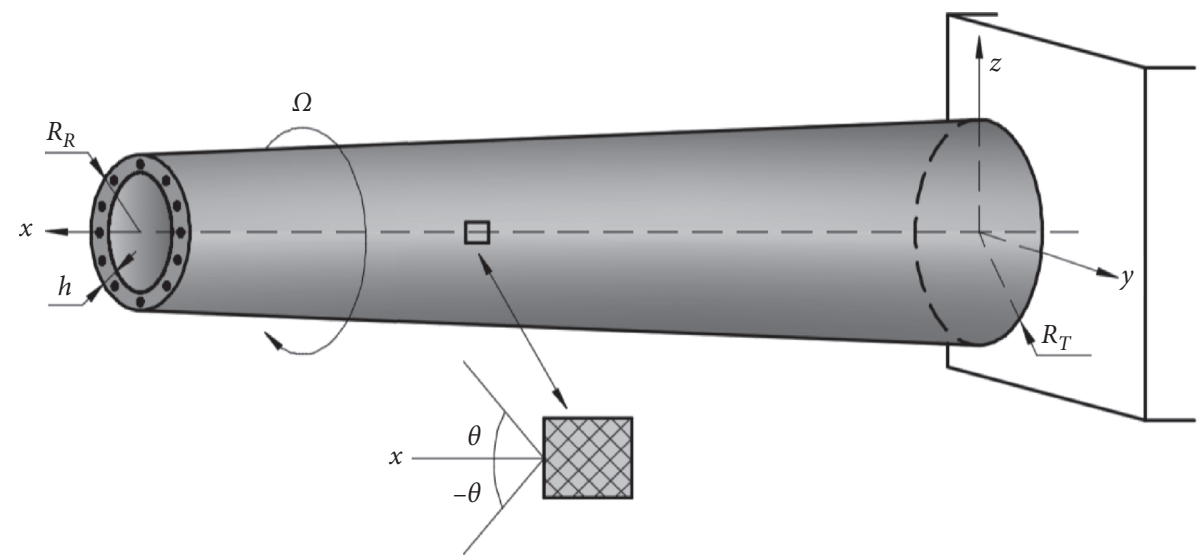

FIGURE 1: Schematic of the rotating tapered composite cutter bar.

2.2. Cutting Force Model. A rotating cutter bar and a fixed workpiece couple have dynamic flexibilities in two orthogonal directions, as shown in Figure 3. It is assumed that the cutter bar has $S$ teeth and the rotating speed $\Omega$ that produce vibration displacements along $y$-axis and $z$-axis directions as shown in Figure 3.
The total regenerative cutting forces acting on the cutter bar contributed by all teeth can be written as [14]

$$
\{F\}=\frac{1}{2} b K_{t}[A(t)]\{\Delta U\},
$$

where

$$
\begin{aligned}
\{F\} & =\left[\begin{array}{ll}
F_{y} & F_{z}
\end{array}\right]^{\mathrm{T}}, \\
\{\Delta U\} & =\left[\begin{array}{ll}
\Delta U_{y} & \Delta U_{z}
\end{array}\right]^{\mathrm{T}}, \\
{[A(t)] } & =\left[\begin{array}{ll}
a_{y y} & a_{y z} \\
a_{z y} & a_{z z}
\end{array}\right]=\left[\begin{array}{ll}
\sum_{j=0}^{S-1}-g_{j}(t)\left[\sin 2 \phi_{j}(t)+K_{r}\left(1-\cos 2 \phi_{j}(t)\right)\right] & \sum_{j=0}^{S-1}-g_{j}(t)\left[\left(1+\cos 2 \phi_{j}(t)\right)+K_{r} \sin 2 \phi_{j}(t)\right] \\
\sum_{j=0}^{S-1} g_{j}(t)\left[\left(1-\cos 2 \phi_{j}(t)\right)-K_{r} \sin 2 \phi_{j}(t)\right] & \sum_{j=0}^{S-1} g_{j}(t)\left[\sin 2 \phi_{j}(t)-K_{r}\left(1+\cos 2 \phi_{j}(t)\right)\right] .
\end{array}\right] .
\end{aligned}
$$

$\Delta U_{y}(t)=U_{y}(t)-U_{y}(t-\tau) ; \quad \Delta U_{z}(t)=U_{z}(t)-U_{z}(t-$ $\tau) . \tau$ denotes the passing interval of the tooth, $b$ denotes the axial cutting depth, $K_{\mathrm{t}}$ and $K_{\mathrm{r}}$ denote tangential and radial cutting coefficients, respectively, and $a_{y y}, a_{y z}, a_{z y}$, and $a_{z z}$ denote directional coefficients that depend on time and the immersion angle $j$ vary with time as $\phi_{j}\left(\phi_{j}=\phi_{p}+j \phi\right.$, in which $\phi_{p}=2 \pi / S$ denotes the cutter pitch angle).

The unit step function $g\left(\phi_{j}\right)$ is used to represent whether the tooth is cut in or cut out:

$$
g\left(\phi_{j}\right)= \begin{cases}1, & \phi_{\text {st }}<\phi_{j}<\phi_{\mathrm{ex}}, \\ 0, & \text { otherwise, }\end{cases}
$$

where $\phi_{\text {st }}$ and $\phi_{\text {ex }}$ are start and exit immersion angles of the cutter to and from the cut. As the cutter bar rotates, the directional coefficient of the cutter changes periodically with time.

It should be noted that $\{\Delta U\}$ has the form $\left[u_{y}(l, t)-u_{y}(l, t-\tau) u_{z}(l, t)-u_{z}(l, t-\tau)\right]^{\mathrm{T}}$ in equations (13) and (14), since the cutting acts at the free end of the cutter bar.
2.3. Critical Rotating Speed and Instability Threshold. In this section, the damped free vibration characteristics of cutting system are analyzed by setting the cutting forces in equations (13) and (14) to zero. Therefore, partial differential equations of motion are firstly discretized by using Galerkin method.

Free vibration solutions to equations of cutting system are

$$
\begin{aligned}
& u_{y}=\sum_{j=1}^{N} U_{y j}(t) \psi_{j}(x), \\
& u_{z}=\sum_{j=1}^{N} U_{z j}(t) \psi_{j}(x),
\end{aligned}
$$

where $\psi_{i}(x)(j=1,2,3, \ldots, N)$ are the mode shapes of a uniform, nonrotating, isotropic, cantilever Euler-Bernoulli beam, which meets the boundary conditions $\left.\psi_{j}(x)\right|_{x=0}=$ $\mathrm{d} \psi_{j}(x) /\left.\mathrm{d} x\right|_{x=0}=\mathrm{d}^{2} \psi_{j}(x) /\left.\mathrm{d} x^{2}\right|_{x=l}=\mathrm{d}^{3} \psi_{j}(x) /\left.\mathrm{d} x^{3}\right|_{x=l}=0$.

Substituting (18) into (13) and (14) with $\{F\}=\{0\}$, the Galerkin procedure yields the following equations of motion:

$$
[M]\{\ddot{U}(t)\}+[C(\Omega)]\{\dot{U}(t)\}+[K(\Omega)]\{U(t)\}=\{0\},
$$




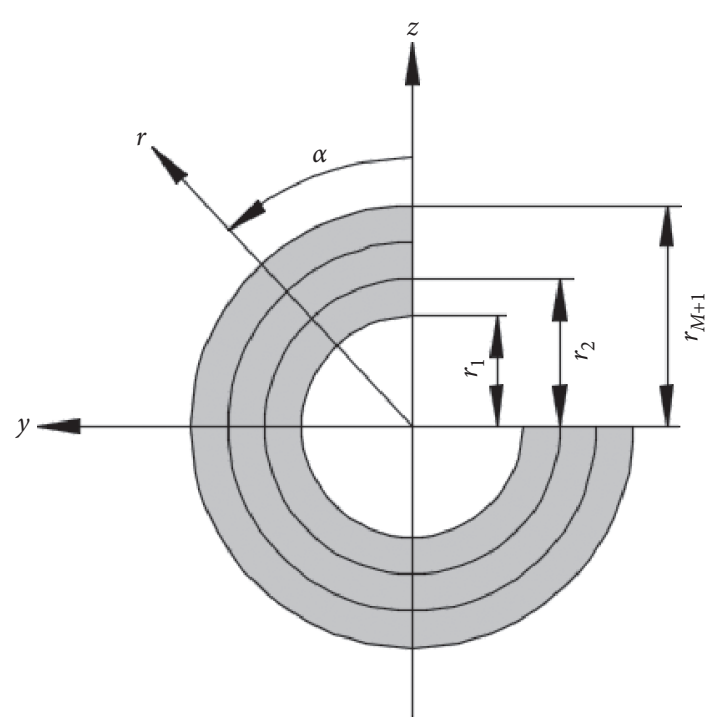

FIGURE 2: $M$-layered laminate of the cutter bar.

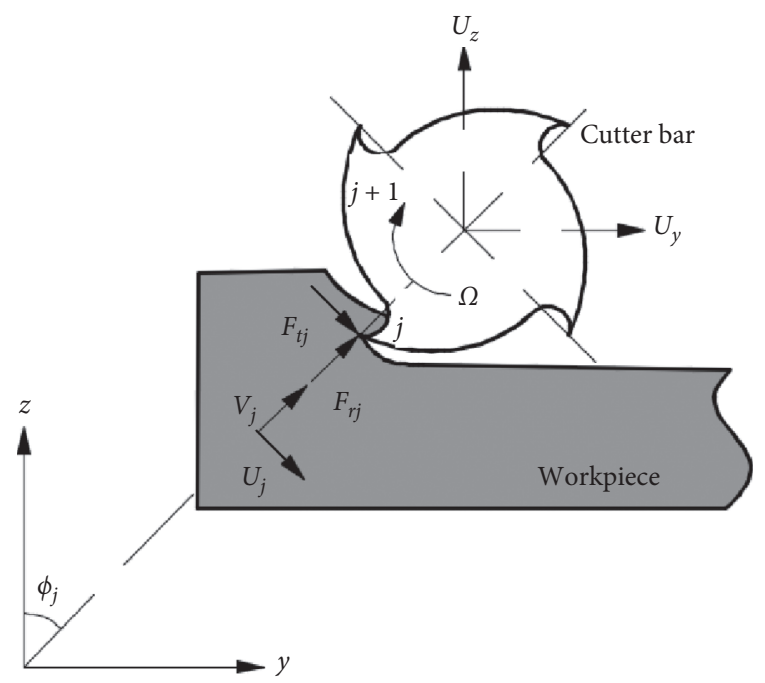

FIGURE 3: Illustration of the cutting force.

where

$$
\begin{aligned}
{[M] } & =\left[\begin{array}{cc}
\overline{\mathbf{M}}-\overline{\mathbf{I}}_{m} & \mathbf{0} \\
\mathbf{0} & \overline{\mathbf{M}}-\overline{\mathbf{I}}_{m}
\end{array}\right], \\
{[C(\Omega)] } & =\left[\begin{array}{cc}
\overline{\mathbf{D}}^{\mathrm{I}}+\overline{\mathbf{D}}^{\mathrm{E}} & -2 \Omega \overline{\mathbf{I}}_{m} \\
2 \Omega \overline{\mathbf{I}}_{m} & \overline{\mathbf{D}}^{\mathrm{I}}+\overline{\mathbf{D}}^{\mathrm{E}}
\end{array}\right], \\
{[K(\Omega)] } & =\left[\begin{array}{cc}
\overline{\mathbf{D}} & \Omega \overline{\mathbf{D}}^{\mathrm{I}} \\
-\Omega \overline{\mathbf{D}}^{\mathrm{I}} & \overline{\mathbf{D}}
\end{array}\right], \\
\{U(t)\} & =\left\{\begin{array}{c}
\left\{U_{y j}(t)\right\} \\
\left\{U_{z j}(t)\right\}
\end{array}\right\} .
\end{aligned}
$$

In equation (20), the mathematical expressions of matrix elements are given as

$$
\begin{aligned}
\int_{0}^{l} m(x) \psi_{i}(x) \psi_{j}(x) \mathrm{d} x & =\bar{M}_{i j}, \\
\int_{0}^{l} I_{m}(x) \psi_{i}(x) \psi_{j}^{\prime \prime}(x) \mathrm{d} x & =\bar{I}_{m i j}, \\
\int_{0}^{l} D_{11}(x) \psi_{i}^{\prime \prime}(x) \psi_{j}^{\prime \prime}(x) \mathrm{d} x & =\bar{D}_{i j}, \\
\int_{0}^{l} C_{I} I(x) \psi_{i}^{\prime \prime}(x) \psi_{j}^{\prime \prime}(x) \mathrm{d} x & =\bar{D}_{i j}^{I}, \\
\int_{0}^{l} C_{E} \psi_{i}(x) \psi_{j}(x) \mathrm{d} x & =\bar{D}_{i j}^{E}, \quad i, j=1,2, \ldots, N,
\end{aligned}
$$

where a prime denotes a derivative with respect to $x$. Note that the damping matrix $[C(\Omega)]$ contains gyroscopic effect and internal damping. The former is only related to damping matrix. The stiffness matrix $[K(\Omega)]$ is associated with internal damping. The presence of the cross-coupled stiffness coefficients may induce the internal damping instability.

In order to determine the external and internal damping coefficients, the following expression can be derived according to the definition of the damping ratio of 1-DOF free vibration systems:

$$
\bar{D}_{11}^{I}+\bar{D}_{11}^{E}=2 \varsigma \sqrt{\bar{D}_{11}\left(\bar{M}_{11}-\bar{I}_{m 11}\right)}
$$

where $\varsigma$ denotes the total damping ratio.

The total damping ratio $\varsigma$ can be expressed as the sum of internal and external damping ratios; namely, $\varsigma=\varsigma_{E}+\varsigma_{I}$.

Then, the internal damping coefficient can be calculated as

$$
\bar{D}_{11}^{I}=2 \varsigma_{I} \sqrt{\bar{D}_{11}\left(\bar{M}_{11}-\bar{I}_{m 11}\right)} .
$$

If $\varsigma$ and $\varsigma_{I}$ are given, the external and internal damping coefficients $C_{\mathrm{E}}$ and $C_{\mathrm{I}}$ can be obtained using equations (22) and (23).

The internal damping ratio $\varsigma_{I}$ is related to the modal loss factors $\eta_{I}$ :

$$
\varsigma_{I}=\frac{1}{2} \eta_{I}
$$

where $\eta_{I}$ denotes the modal loss factors, which can be defined by using an energy approach [17].

$$
\eta_{I}=\frac{1}{2 \pi} \frac{\{X\}^{T}[\widehat{C}]\{X\}}{\{X\}^{T}[\widehat{K}]\{X\}},
$$

where $\{X\}$ is the undamped mode deflection of the tapered nonrotating cutter bar and $[\widehat{K}]$ and $[\widehat{C}]$ are the stiffness and damping matrices, respectively, which have the forms

$$
\begin{aligned}
& {[\widehat{C}]=\left[\begin{array}{cc}
\mathbf{D}^{\mathrm{I}} & 0 \\
0 & \mathbf{D}^{\mathrm{I}}
\end{array}\right],} \\
& {[\widehat{K}]=\left[\begin{array}{ll}
\overline{\mathbf{D}} & 0 \\
0 & \overline{\mathbf{D}}
\end{array}\right] .}
\end{aligned}
$$

In the previous equations, the elements of damping matrix are given by [15] 


$$
\begin{aligned}
& \int_{0}^{l} D_{11}^{I}(x) \psi_{i}^{\prime \prime}(x) \psi_{j}^{\prime \prime}(x) \mathrm{d} x=D_{i j}^{I}, \\
& D_{11}^{I}(x)=\frac{\pi}{4} \sum_{k=1}^{M} \bar{\eta}_{i s} \bar{Q}_{s j}\left[r_{k+1}^{4}(x)-r_{k}^{4}(x)\right], \quad i, j, s=1,2,6 .
\end{aligned}
$$

$\bar{\eta}_{i s}$ denotes the off-axis damping dissipation factor of the composite layer. The detailed expressions can be found in the Appendix.

For a tapered rotating composite cutter bar, equation (19) provides the following characteristic problem:

$$
\left[\begin{array}{cc}
{[0]} & {[I]} \\
-[M]^{-1}[K(\Omega)] & -[M]^{-1}[C(\Omega)]
\end{array}\right]\left(\begin{array}{c}
\{U(t)\} \\
\{\dot{U}(t)\}
\end{array}\right)=\lambda\left(\begin{array}{c}
\{U(t)\} \\
\{\dot{U}(t)\}
\end{array}\right),
$$

where $[0]$ and $[I]$ denote the zero matrix and identity matrix, respectively.

The eigenvalues of equation (28) are $\lambda_{k}=\sigma_{k}+i \omega_{k},(k=1,2, \ldots)$, where the real part $\sigma_{k}$ is the decay rate and the imaginary part $\omega_{k}$ is the whirl frequency, which are rotating-speed-dependent. In order to obtain the critical rotating speed and instability threshold of the rotating composite cutter bar, the Campbell diagram and decay rate plot are needed.

2.4. Stability Analysis. The discretized dynamic equation of the cutting system can be represented as follows:

$$
\begin{gathered}
{[M]\{\ddot{U}(t)\}+[C(\Omega)]\{\dot{U}(t)\}+[K(\Omega)]\{U(t)\}} \\
=\frac{b K_{t}}{2}[A(t)][Z]\{\{U(t)\}-\{U(t-\tau)\}\},
\end{gathered}
$$

where the elements of the matrix [Z] have the following form:

$$
Z_{i j}=\psi_{i}(l) \psi_{j}(l), \quad i, j=1,2, \ldots, N
$$

Note that there will be effects on the chatter stability of cutting system due to the time-delay terms $\{U(t-\tau)\}$ in equation (29).

The time-dependent coefficients and the delay terms bring difficultly to the solution of the differential equations. Minis and Yanushevsky [18] presented a comprehensive analytical method in solving this problem, which is complicated and involves extensive computation. Altintas and Budak [14] proposed a simple frequency domain method for a lumped mass model, which is extended and used here for analytical prediction of stability in the cutting system.

According to the method of Altintas and Budak [14], the periodic directional matrix $[A(\mathrm{t})]$ is firstly expanded into a Fourier series, and only its average component (constant term or the zero order solution) is considered:

$$
\left[A_{0}\right]=\frac{1}{T} \int_{0}^{T}[A(t)] \mathrm{d} t=\frac{1}{\varphi_{p}} \int_{\varphi_{\mathrm{st}}}^{\varphi_{\mathrm{ex}}}[A(\varphi)] \mathrm{d} \varphi=\frac{S}{2 \pi}\left[\begin{array}{cc}
\alpha_{y y} & \alpha_{y z} \\
\alpha_{z y} & \alpha_{z z}
\end{array}\right] .
$$

The elements in directional matrix can be written as [14]

$$
\begin{aligned}
& \alpha_{y y}=\frac{1}{2}\left(\cos 2 \phi-2 K_{r} \phi+K_{r} \sin 2 \phi\right)_{\varphi_{\mathrm{st}}}^{\varphi_{\mathrm{ex}}}, \\
& \alpha_{y z}=\frac{1}{2}\left(-\sin 2 \phi-2 \phi+K_{r} \sin 2 \phi\right)_{\varphi_{\mathrm{st}}}^{\varphi_{\mathrm{ex}}}, \\
& \alpha_{z y}=\frac{1}{2}\left(-\sin 2 \phi+2 \phi+K_{r} \sin 2 \phi\right)_{\varphi_{\mathrm{st}}}^{\varphi_{\mathrm{ex}}}, \\
& \alpha_{z z}=\frac{1}{2}\left(-\cos 2 \phi-2 K_{r} \phi-K_{r} \sin 2 \phi\right)_{\varphi_{\mathrm{st}}}^{\varphi_{\mathrm{ex}}} .
\end{aligned}
$$

Accordingly, the cutting force in equation (15) becomes

$$
\{F\}=\frac{1}{2} b K_{t}\left[A_{0}\right]\{\Delta U\}
$$

where $\left[A_{0}\right]$ is a time invariant matrix.

Replacing $[A(t)]$ with $\left[A_{0}\right]$, equation (29) becomes

$$
[M]\{\ddot{U}(t)\}+[C(\Omega)]\{\dot{U}(t)\}+[K(\Omega)]\{U(t)\}=\frac{1}{2} K_{t} b\left[G_{0}\right]\{\Delta U\},
$$

where

$$
\begin{aligned}
& {\left[G_{0}\right]=\frac{S}{2 \pi}\left[\begin{array}{ll}
\alpha_{y y}[Z] & \alpha_{y z}[Z] \\
\alpha_{z y}[Z] & \alpha_{z z}[Z]
\end{array}\right],} \\
& \{\Delta U\}=\{U(t)\}-\{U(t-\tau)\} .
\end{aligned}
$$

The cutting forces are treated as concentrated loads at the tip of the cutter bar $(x=l)$, so the cutting force matrix $\left[G_{0}\right]$ is mode-functions-dependent (e.g., the elements of $\left[G_{0}\right]$ have the form $\alpha_{y y}[Z]=\alpha_{y y} \psi_{i}(l) \psi_{j}(l)$, etc.).

The zero-order solution is adequate for prediction of stability in most cases [19-21], because most of the vibration energy remains in the vicinity of modal frequencies, and the harmonics are low-pass-filtered by the structural modes [21].

By conducting Laplace transformation on equation (34) and assuming $\nu=\lambda+i \omega$, it can be found that the value of $\nu$ is connected with system stability:

If $\lambda>0$, the system is in unstable state

If $\lambda<0$, the system is in stable state

If $\lambda=0$, the system is in the critical state between stable and unstable states

Let $\lambda=0$; by substituting $\nu=i \omega_{c}$ into the equation after Laplace transformation of equation (34), the following expression can be written as 


$$
\begin{gathered}
-\omega_{c}^{2}[M]+i \omega_{c}[C \Omega]+[K \Omega]\{U\} \\
=\frac{1}{2} K_{t} b\left[G_{0}\right] 1-e^{-i \omega_{c} T}\{U\},
\end{gathered}
$$

where $\omega_{c}$ denotes the chatter frequency.

The transfer function has the following form:

$$
\left[G\left(\omega_{c}, \Omega\right)\right]=\left[-\omega_{c}^{2}[M]+i \omega_{c}[C(\Omega)]+[K(\Omega)]\right]^{-1} \text {. }
$$

Equation (36) can be rewritten as

$$
\left[[I]-\frac{1}{2} K_{t} b\left[G_{0}\right]\left[G\left(\omega_{c}, \Omega\right)\right]\left(1-e^{-i \omega_{c} T}\right)\right]\{U\}=\{0\} .
$$

The system of linear equation (38) has a nontrivial solution if its determinant is zero:

$$
\operatorname{det}\left|\left[[I]-\frac{1}{2} K_{t} b\left[G_{0}\right]\left[G\left(\omega_{c}, \Omega\right)\right]\left(1-e^{-i \omega_{c} T}\right)\right]\right|=0 .
$$

The stability of the cutting system can be transformed into the characteristic value of the following characteristic equation:

$$
\operatorname{det}\left[[I]+\Lambda\left[E_{0}\left(\omega_{c}, \Omega\right)\right]\right]=0,
$$

where

$$
\begin{gathered}
\Lambda=-\frac{S}{4 \pi} K_{t} b\left(1-e^{-i \omega_{c} T}\right), \\
{\left[E_{0}\left(\omega_{c}, \Omega\right)\right]=\frac{2 \pi}{S}\left[G_{0}\right]\left[G\left(\omega_{c}, \Omega\right)\right] .}
\end{gathered}
$$

For a given $\omega_{c}$, equation (40) gives a set of complex eigenvalues:

$$
\Lambda=\Lambda_{R}+i \Lambda_{I}
$$

The limit cutting depth in cutting process can be given from equation (41) as

$$
b_{\lim }=-\frac{\Lambda}{\left(4 \pi / S K_{t}\right)\left(1-e^{-i \omega_{c} T}\right)} .
$$

Substituting $\Lambda=\Lambda_{R}+i \Lambda_{I}$ and $e^{-i \omega_{c} T}=\cos \omega_{c} T-$ $i \sin \omega_{c} T$ into equation (44), one has

$$
\begin{aligned}
b_{\lim }= & -\frac{2 \pi}{S K_{t}}\left[\frac{\Lambda_{R}\left(1-\cos \omega_{c} T\right)+\Lambda_{I} \sin \omega_{c} T}{1-\cos \omega_{c} T}\right. \\
& \left.+i \frac{\Lambda_{I}\left(1-\cos \omega_{c} T\right)-\Lambda_{R} \sin \omega_{c} T}{1-\cos \omega_{c} T}\right] .
\end{aligned}
$$

Since $b_{\text {lim }}$ is a real number, the imaginary part of equation (45) must vanish:

$$
\begin{gathered}
\Lambda_{I}\left(1-\cos \omega_{c} T\right)-\Lambda_{R} \sin \omega_{c} T=0, \\
\text { or } \kappa=\frac{\Lambda_{I}}{\Lambda_{R}}=\frac{\sin \omega_{c} T}{1-\cos \omega_{c} T} .
\end{gathered}
$$

From equation (47),

$$
\omega_{c} T=\cos ^{-1}\left(\frac{1-\kappa^{2}}{1+\kappa^{2}}\right)=-\cos ^{-1} 2 \psi .
$$

Note that $\kappa=\Lambda_{I} / \Lambda_{R}=\tan ^{-1} \psi$, and $\psi$ is the phase angle. From equation (48),

$$
T=\frac{\varepsilon+2 j \pi}{\omega_{c}},
$$

where $\varepsilon=\pi-2 \psi$ denotes the phase shift of the vibration mark between the present tooth and the previous tooth. Thus, the rotating speed $\Omega$ is simply calculated as $\Omega=60 / S T$.

By substituting equation (47) into the real part of equation (45), the final expression for limit cutting depth is

$$
b_{\lim }=-\frac{2 \pi \Lambda_{R}}{S K_{t}}\left(1+\kappa^{2}\right),
$$

where $\psi$ denotes the phase angle and $\varepsilon$ denotes the phase shift of the vibration mark between the present tooth and the previous tooth.

It is important to note that, in our model, the structural transfer function changes with rotating speed (see equation (37)). Thus, the solution algorithm presented by Altintas and Budak [14] cannot be directly applied here, since the stability problem deals with the nonrotating cutter bar in Altintas and Budak's model [14].

In this paper, to predict the stability lobes of the cutting system, the method developed by Altintas and Budak [14] is extended by constructing an iterative scheme.

The stability lobes can be calculated according to the following procedure:

(1) Calculate the directional matrix in accordance with the milling cutter's material and geometrical parameters

(2) Start a loop incrementing the spindle speed $\Omega$

(3) Calculate the natural frequency corresponding to the rotating speed

(4) Scan the chatter frequency $\omega_{c}$ by using the natural frequency as the reference, and calculate the transfer function

(5) Calculate real and imaginary parts according to equation (40), and solve the critical axial cutting depth $b_{\lim }$ and the corresponding rotating speed $\Omega$

(6) If the difference between the rotating speed obtained in step 5 and input rotating speed in step 2 satisfies the required precision, plot the stability lobes by using $\Omega$ the $x$-axis and $b_{\lim }$ as the $y$-axis, respectively; otherwise, repeat the iterative procedures until the results converge

(7) Select the new $j$ and calculate the adjacent lobes

\section{Numerical Results and Discussion}

Employing the formulation derived in the previous sections, the modal loss factor, the natural frequencies, decay ratio for 
the rotating composite cutter bar, and the stability lobes of the cutting process with the cutter bar are calculated in this section. To validate the developed model of this paper, comparisons are made between the present solutions and those reported in literature and obtained using ANSYS.

\subsection{Validation}

3.1.1. Example 1. The first example is circular tubular composite cantilever beams. Their modal loss factors are calculated using equation (25) and compared with those available in [17] based on three-dimensional beam and shell finite element. In this example, circular tubular composite cantilever beams of mid-surface diameter $d=352 \mathrm{~mm}$ and wall thickness $h=10.16 \mathrm{~mm}$ are considered. The first bending loss factor and frequency obtained using the present model are shown in Table 1 together with those of [17]. In this analysis, three shape functions are utilized for obtaining the convergent results. As can be seen from the table, our results are close to those predicted by the finite element model, except the aspect ratio $l / d=6.5$, which is not in the applicable range of Euler-Bernoulli beam theory.

3.1.2. Example 2. The second example is a tapered composite cutter bar. The rotation of the cutter bar is not considered here. In this example, the external diameter of the tapered composite cutter bar at the free end is $0.06 \mathrm{~m}$, and the wall thickness $h=0.04 \mathrm{~m}$. The length $l$ and the external diameter of the fixed end can be determined by the given taper and aspect ratios. The stacking sequence of the composite cutter bar is represented as $[ \pm \theta]_{8}$.

The cutter's material properties are listed in Table 2, and its natural frequencies and dampings are presented in Tables 3-5 which show the effect of ply angle, aspect ratio, and taper ratio, respectively. Figure 4 presents the 3D FEM structural model of the tapered composite cutter bar obtained by ANSYS FE code. The structural discretization for the tapered cutter bar is performed by using the sweeping algorithms for mesh generation of hexahedron. In total, 8032 elements are generated. Rayleigh damping is set, and the modal analysis results are obtained by the QR Damped eigenvalue extraction method.

As shown in Tables 3-5, the results based on the present model are consistent with the results of ANSYS finite element dynamic analysis. Moreover, it can be seen from Tables 3-5 that the convergence of results is good with respect to the numbers of mode shape functions $N$. In fact, only three modal functions are found to be adequate for convergence.

3.1.3. Example 3. The third example is a rotating tapered composite cutter bar; all of its properties are the same as those of the second example. The first whirling forward (FW1) and backward (BW1) frequencies corresponding to different rotational speeds for the rotating tapered composite cutter bar of different ply angles are presented in
TABle 1: Modal damping of circular composite beams.

\begin{tabular}{lcccc}
\hline \multirow{2}{*}{ Lamination } & \multicolumn{4}{c}{ Modal loss factor (\%) } \\
& & \multicolumn{3}{c}{ First flapping } \\
& & Beam [17] & Shell [17] & Present \\
\hline \multirow{3}{*}{]$_{16}$} & $l / d=6.5$ & 0.85 & 1.02 & 0.65 \\
& $l / d=13$ & 0.70 & 0.78 & 0.65 \\
& $l / d=26$ & 0.66 & 0.70 & 0.65 \\
& $l / d=104$ & 0.65 & - & 0.65 \\
\hline$[90]_{16}$ & $l / d=6.5$ & 2.37 & 2.37 & 2.34 \\
& $l / d=13$ & 2.35 & 2.25 & 2.34 \\
& $l / d=26$ & 2.35 & 2.17 & 2.34 \\
{$\left[0_{2} / 90_{2} / 45_{2} /-45_{2} /\right]_{s}$} & $l / d=13$ & 1.44 & 1.45 & 1.31 \\
& $l / d=26$ & 1.44 & 1.44 & 1.31 \\
& $l / d=104$ & 2.35 & - & 2.34 \\
\hline$[45 /-45]_{8}$ & $l / d=6.5$ & 2.42 & 2.36 & 2.38 \\
& $l / d=13$ & 2.44 & 2.39 & 2.38 \\
& $l / d=26$ & 2.45 & 2.39 & 2.38 \\
& $l / d=104$ & 2.45 & - & 2.38 \\
\hline
\end{tabular}

Table 6 with those obtained using ANSYS. It can be seen from Table 6 that the difference between the present model and ANSYS solution in obtaining the whirling frequencies is small.

3.1.4. Example 4. The fourth example is a milling process with a 2-DOF cutter bar. Figure 5 shows plots of stability lobes in $\left(b_{\text {lim }} \Omega\right)$ plane predicted using the present model and the model by Altintas and Budak [14]. The structural dynamic parameters of the cutter bar and the process parameters involved are obtained from the same work [14]: $\omega_{n x}=389 \mathrm{~Hz}$, $\omega_{n y}=348 \mathrm{~Hz}, \quad k_{x}=5.54 \times 10^{7} \mathrm{~N} / \mathrm{m}, \quad k_{y}=2.14 \times 10^{7} \mathrm{~N} / \mathrm{m}$, $\varsigma_{x}=0.04, \varsigma_{y}=0.1, K_{t}=1500 \mathrm{MPa}, K_{r}=0.3, S=8, \Phi_{\mathrm{st}}=0^{\circ}$, and $\Phi_{\text {ex }}=90^{\circ}$. The gyroscopic effect of the cutter bar is considered in the present model but not in the model of [14]. As a result, the limiting depth of cut for the rotating-bar case is lower than that for the non-rotating-bar case, as shown in Figure 5. If the rotation of the cutter bar is neglected, the results of the present model can be reduced into the result of [14].

3.2. Modal Loss Factors. In this subsection, the modal loss factors of a tapered composite cutter bar are calculated by the present method. The structural and material properties and the stacking sequence of this cutter bar are identical to those used in the second example, which will also be used in later subsections.

Employing the Galerkin method convergence of the loss factor of the cutter bar corresponding to the mode shape functions' number $N$ is described in Table 7. Various ply angles are considered, and the maximum value of $N$ in the calculation is 4 . It is seen that 3 terms' results are the same as 2 terms' results. So, $N=3$ will be used in the following subsections, unless otherwise specified. 
TABLE 2: Composite material properties [12]

\begin{tabular}{ccccccccc}
\hline$\rho\left(\mathrm{kg} / \mathrm{m}^{3}\right)$ & $E_{11}(\mathrm{GPa})$ & $E_{22}(\mathrm{GPa})$ & $G_{12}(\mathrm{GPa})$ & $v_{21}$ & $\eta_{1}(\%)$ & $\eta_{2}(\%)$ & $\eta_{4}(\%)$ & $\eta_{5}=\eta_{6}(\%)$ \\
\hline 1446.2 & 172.7 & 7.2 & 3.76 & 0.3 & 0.45 & 4.22 & 7.05 & 7.05 \\
\hline
\end{tabular}

TABLE 3: The natural frequencies of the nonrotating tapered composite cutter bar with different ply angles $(\varsigma=0.01, L / d=10$, and $\sigma=0.75)$.

\begin{tabular}{|c|c|c|c|c|c|c|c|c|c|c|c|}
\hline \multirow{3}{*}{$\theta$} & \multirow{3}{*}{ Mode } & \multicolumn{5}{|c|}{ Natural frequency $(\mathrm{Hz})$} & \multicolumn{5}{|c|}{ Damping } \\
\hline & & \multicolumn{4}{|c|}{ Present } & \multirow{2}{*}{ ANSYS } & \multicolumn{4}{|c|}{ Present } & \multirow{2}{*}{ ANSYS } \\
\hline & & $N=1$ & $N=2$ & $N=3$ & $N=4$ & & $N=1$ & $N=2$ & $N=3$ & $N=4$ & \\
\hline \multirow{3}{*}{$0^{\circ}$} & 1 & 288.23 & 285.80 & 283.35 & 283.35 & 283.92 & -20.03 & -18.89 & -18.17 & -18.17 & -17.88 \\
\hline & 2 & 1555.08 & 1552.42 & 1550.37 & 1550.37 & 1549.86 & -36.87 & -35.44 & -35.01 & -35.01 & -34.75 \\
\hline & 3 & - & 4198.44 & 4197.98 & 4197.98 & 4197.60 & - & -152.95 & -152.42 & -152.42 & -152.11 \\
\hline \multirow{3}{*}{$45^{\circ}$} & 1 & 156.03 & 153.48 & 152.65 & 152.65 & 152.85 & -11.73 & -10.33 & -9.74 & -9.74 & -9.35 \\
\hline & 2 & 835.78 & 833.63 & 832.36 & 832.36 & 832.28 & -38.25 & -37.13 & -36.43 & -36.43 & -36.01 \\
\hline & 3 & - & 2254.38 & 2252.97 & 2252.97 & 2252.65 & - & -193.11 & -192.07 & -192.07 & -191.67 \\
\hline \multirow{3}{*}{$90^{\circ}$} & 1 & 60.05 & 58.36 & 56.95 & 56.95 & 57.06 & -6.35 & -4.98 & -3.68 & -3.68 & -3.04 \\
\hline & 2 & 319.45 & 316.92 & 315.03 & 315.03 & 315.35 & -41.22 & -39.36 & -38.27 & -38.27 & -37.46 \\
\hline & 3 & - & 856.22 & 854.55 & 854.55 & 854.97 & - & -266.75 & -265.38 & -265.38 & -264.52 \\
\hline
\end{tabular}

TABLE 4: The natural frequencies of the non-rotating tapered composite cutter bar with different aspect ratios $\left(\varsigma=0.01, \theta=0^{\circ}\right.$, and $\left.\sigma=0.75\right)$.

\begin{tabular}{|c|c|c|c|c|c|c|c|c|c|c|c|}
\hline \multirow{3}{*}{$L / d$} & \multirow{3}{*}{ Mode } & \multicolumn{5}{|c|}{ Natural frequency $(\mathrm{Hz})$} & \multicolumn{5}{|c|}{ Damping } \\
\hline & & \multicolumn{4}{|c|}{ Present } & \multirow{2}{*}{ ANSYS } & \multicolumn{4}{|c|}{ Present } & \multirow{2}{*}{ ANSYS } \\
\hline & & $N=1$ & $N=2$ & $N=3$ & $N=4$ & & $N=1$ & $N=2$ & $N=3$ & $N=4$ & \\
\hline \multirow{3}{*}{10} & 1 & 288.23 & 285.80 & 283.35 & 283.35 & 283.92 & -20.03 & -18.89 & -18.17 & -18.17 & -17.88 \\
\hline & 2 & 1555.08 & 1552.42 & 1550.37 & 1550.37 & 1549.86 & -36.87 & -35.44 & -35.01 & -35.01 & -34.75 \\
\hline & 3 & - & 4198.44 & 4197.98 & 4197.98 & 4197.60 & - & -152.95 & -152.42 & -152.42 & -152.11 \\
\hline \multirow{3}{*}{12} & 1 & 201.72 & 198.45 & 196.99 & 196.99 & 196.76 & -14.09 & -13.21 & -12.61 & -12.61 & -12.35 \\
\hline & 2 & 1082.34 & 1079.54 & 1077.54 & 1077.54 & 1077.98 & -25.97 & -24.68 & -24.38 & -24.38 & -24.02 \\
\hline & 3 & - & 2929.66 & 2927.85 & 2927.85 & 2928.02 & - & -107.83 & -107.11 & -107.11 & -106.77 \\
\hline \multirow{3}{*}{15} & 1 & 129.51 & 126.99 & 125.02 & 125.02 & 124.69 & -9.06 & -8.47 & -8.07 & -8.07 & -7.73 \\
\hline & 2 & 693.79 & 691.68 & 689.48 & 689.48 & 688.92 & -16.85 & -15.93 & -15.64 & -15.64 & -15.32 \\
\hline & 3 & - & 1882.45 & 1881.65 & 1881.65 & 1881.03 & - & -69.62 & -69.11 & -69.11 & -68.59 \\
\hline
\end{tabular}

TABLE 5: The natural frequencies of the non-rotating tapered composite cutter bar with different taper ratios $\left(\varsigma=0.01, \theta=0^{\circ}, L / d=10\right)$.

\begin{tabular}{|c|c|c|c|c|c|c|c|c|c|c|c|}
\hline \multirow{3}{*}{$\sigma$} & \multirow{3}{*}{ Mode } & \multicolumn{5}{|c|}{ Natural frequency $(\mathrm{Hz})$} & \multicolumn{5}{|c|}{ Damping } \\
\hline & & \multicolumn{4}{|c|}{ Present } & \multirow{2}{*}{ ANSYS } & \multicolumn{4}{|c|}{ Present } & \multirow{2}{*}{ ANSYS } \\
\hline & & $N=1$ & $N=2$ & $N=3$ & $N=4$ & & $N=1$ & $N=2$ & $N=3$ & $N=4$ & \\
\hline \multirow{3}{*}{1} & 1 & 197.69 & 194.16 & 192.85 & 192.85 & 192.58 & -11.98 & -10.95 & -10.20 & -10.20 & -9.67 \\
\hline & 2 & 1120.92 & 1188.45 & 1186.79 & 1186.79 & 1186.35 & -28.73 & -27.18 & -26.52 & -26.52 & -26.03 \\
\hline & 3 & - & 3214.05 & 3213.02 & 3213.02 & 3212.76 & - & -143.85 & -143.19 & -143.19 & -142.76 \\
\hline \multirow{3}{*}{0.75} & 1 & 221.65 & 218.79 & 216.99 & 216.99 & 216.53 & -15.48 & -14.57 & -13.90 & -13.90 & -13.45 \\
\hline & 2 & 1213.02 & 1210.45 & 1209.01 & 1209.01 & 1208.75 & -35.17 & -33.99 & -33.46 & -33.46 & -33.01 \\
\hline & 3 & - & 3349.10 & 3347.52 & 3347.52 & 3347.92 & - & -167.68 & -166.99 & -166.99 & -166.63 \\
\hline \multirow{3}{*}{0.5} & 1 & 367.43 & 363.06 & 362.05 & 362.05 & 361.78 & -25.69 & -24.68 & -24.11 & -24.11 & -23.72 \\
\hline & 2 & 1656.99 & 1654.52 & 1652.83 & 1652.83 & 1653.02 & -45.13 & -44.25 & -43.67 & -43.67 & -43.12 \\
\hline & 3 & - & 4522.32 & 4521.27 & 4521.27 & 4520.85 & - & -196.99 & -196.40 & -196.40 & -196.05 \\
\hline
\end{tabular}

Figure 6 shows the variation of modal loss factor of the composite cutter bar with ply angle. It can be seen that the loss factor in the first mode increases with the value of ply angle increasing from $0^{\circ}$ to $81^{\circ}$. It is minimum at $0^{\circ}$ ply angle, 


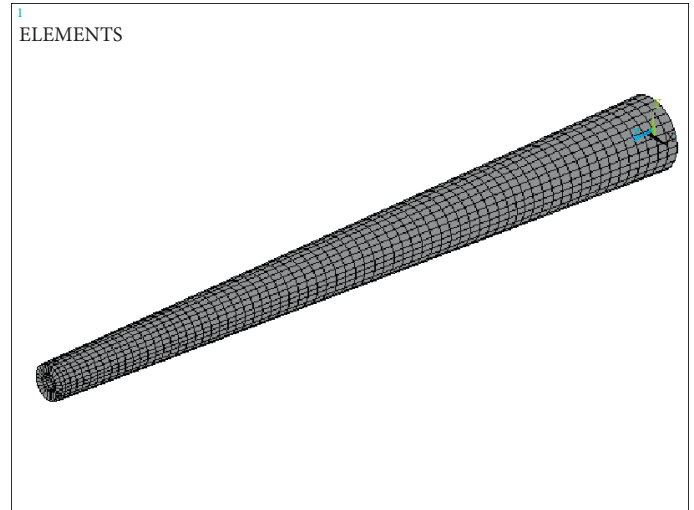

Figure 4: The 3D FEM structural model of the tapered composite cutter bar.

TABLE 6: The first whirling frequencies (in $\mathrm{Hz}$ ) of the rotating tapered composite cutter bar with different rotating speeds $(\varsigma=0.01, L / d=10$, and $\sigma=0.5)$.

\begin{tabular}{|c|c|c|c|c|c|c|c|}
\hline \multirow{3}{*}{ Rotational speed (rad/s) } & \multirow{3}{*}{ Mode } & \multicolumn{6}{|c|}{$\theta$} \\
\hline & & \multicolumn{2}{|r|}{$0^{\circ}$} & \multicolumn{2}{|r|}{$45^{\circ}$} & \multicolumn{2}{|r|}{$90^{\circ}$} \\
\hline & & ANSYS & Present $(N=3)$ & ANSYS & Present $(N=3)$ & ANSYS & Present $(N=3)$ \\
\hline \multirow{2}{*}{0} & BW1 & 328.76 & 329.26 & 176.26 & 176.81 & 54.09 & 54.42 \\
\hline & FW1 & 328.76 & 329.26 & 176.26 & 176.81 & 54.09 & 54.42 \\
\hline \multirow{2}{*}{500} & BW1 & 328.46 & 329.18 & 175.80 & 176.63 & 53.70 & 54.37 \\
\hline & FW1 & 329.09 & 329.35 & 176.73 & 176.90 & 54.49 & 54.51 \\
\hline \multirow{2}{*}{1000} & BW1 & 328.14 & 329.09 & 175.34 & 176.44 & 53.31 & 54.32 \\
\hline & FW1 & 329.41 & 329.44 & 177.19 & 177.09 & 54.89 & 54.59 \\
\hline \multirow{2}{*}{5000} & BW1 & 327.61 & 328.41 & 174.73 & 175.97 & 52.27 & 53.83 \\
\hline & FW1 & 330.96 & 330.12 & 178.01 & 177.68 & 55.96 & 55.22 \\
\hline
\end{tabular}

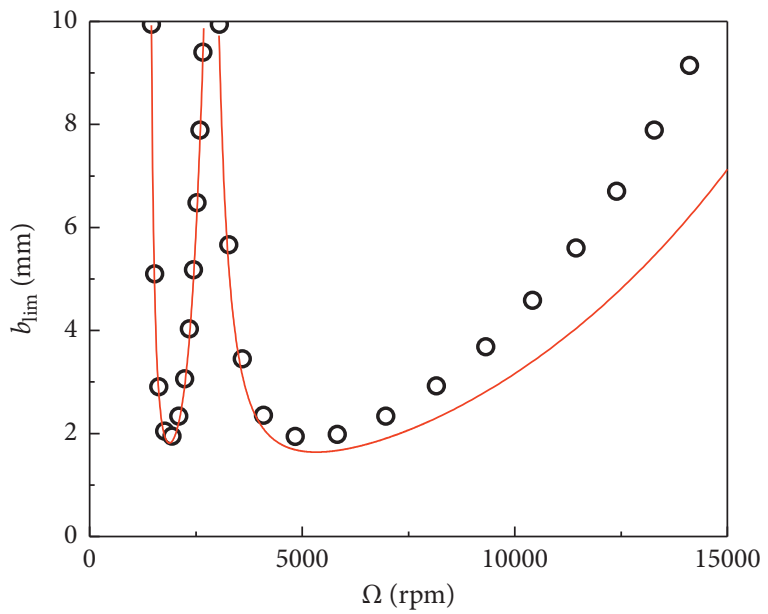

- Altintas and Budak [14]

- Present

FIGURE 5: Comparing the stability lobe diagrams for the cutter bar with and without gyroscopic effects.

about $0.45 \%$, and has a maximum value, about $4.28 \%$, at $81^{\circ}$ ply angle. An insignificant amount of reduction in the modal loss factor is observed in the range of $81^{\circ} \sim 90^{\circ}$ (about $4.22 \%$ for $90^{\circ}$ ply angle). Such behavior is explained by the fact that the closer the fiber is oriented to $90^{\circ}$, the greater the modal loss factor is since the transversal specific damping capacity is greater than that along longitudinal direction (see Table 2).

Figures 7 and 8 show the variation of the modal dissipation factors with the taper and aspect ratios of the tapered composite cutter bar, respectively. It is clear from Figure 7 that the effect of aspect ratio on the modal dissipation factor is negligible; this is in agreement with that obtained by Saravanos et al. [17]. Also, it is shown from Figure 8 that taper ratio has no obvious effect on the modal dissipation factor.

3.3. Critical Rotating Speed and Instability Threshold. Next, the whirl frequency, the decay rate, the critical rotating speed, and the instability threshold of a tapered rotating composite cutter bar are analyzed by using (28). The lamination scheme and geometric properties of the cutter remain the same as previous examples.

Figure 9 shows the effect of internal and external damping on the first whirl frequency and decay rate of the tapered composite cutter bar. It can be noted from Figure 9(a) that, for three cases, namely, without external, with internal and external damping, and without internal damping, the difference of these plots is very small. This shows the effect of internal and external damping is not 
TABLE 7: The loss factors of the composite cutter bar by different numbers of mode shape functions $(L / d=10$ and $\sigma=1)$.

\begin{tabular}{lccc}
\hline$N$ & & $\theta$ & \\
& $0^{\circ}(\%)$ & $45^{\circ}(\%)$ & $90^{\circ}(\%)$ \\
\hline 1 & 0.4506 & 1.1241 & 4.2203 \\
2 & 0.4500 & 1.1236 & 4.2200 \\
3 & 0.4500 & 1.1236 & 4.2200 \\
4 & 0.4500 & 1.1236 & 4.2200 \\
\hline
\end{tabular}

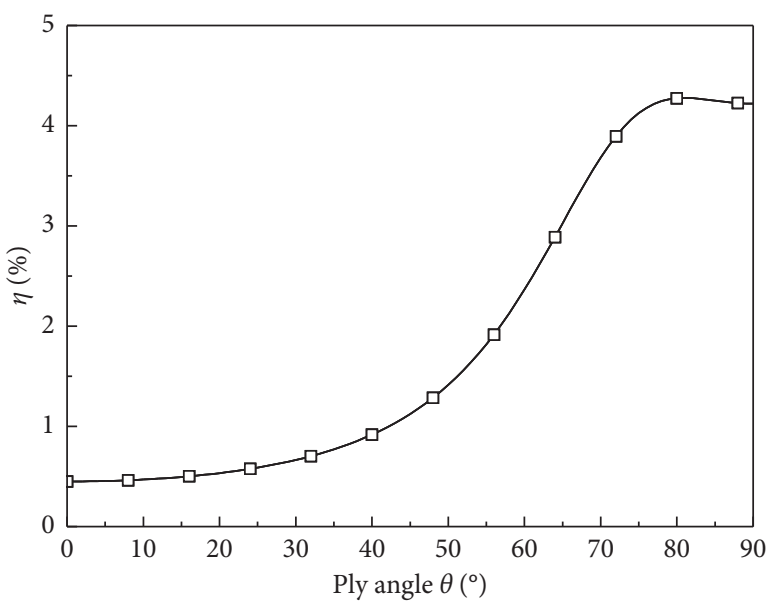

FIGURE 6: Variation of modal loss factor with ply angle $(l / d=10$ and $\sigma=0.5)$.

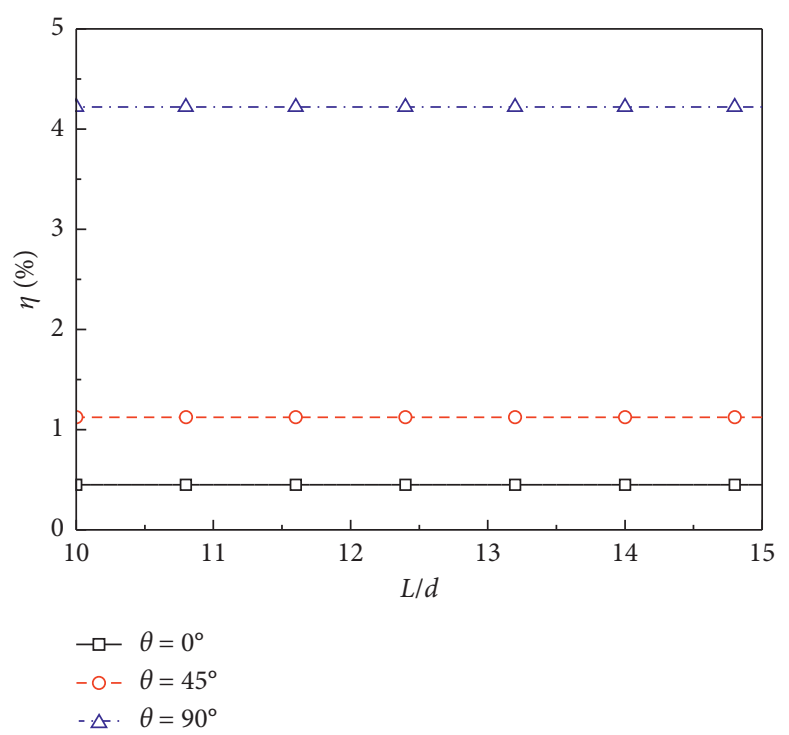

FIGURE 7: Variation of modal loss factor with aspect ratio $(\sigma=1)$.

important. As shown in Figure 9(a), when the rotating speed is increased, due to the gyroscopic effect, the whirl frequencies split into the upper and lower frequency branches. The intersection point of the line $\omega_{d 1}=\Omega$ with the lower frequency branch gives the first critical rotating speed (342 rad/s). Figure 9(a) is generally known as a Campbell diagram.

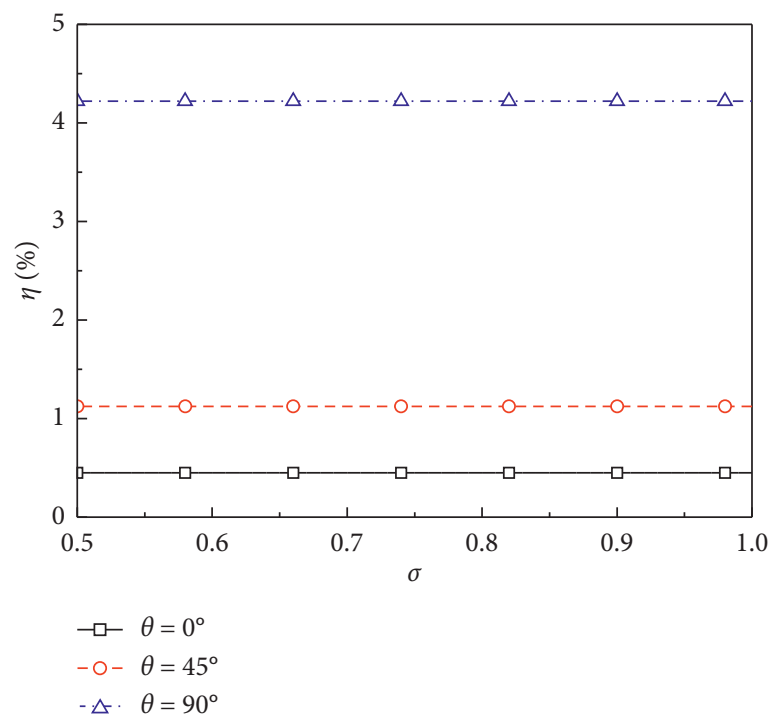

Figure 8: Variation of modal loss factor with taper ratio $(l / d=10)$.

It is seen from Figure 9(b) that internal damping and external damping have a significant effect on the decay rate versus rotating speed curves. If the internal damping is not equal to zero, the decay rate versus rotating speed curves can be divided into two branches; the decay of the backward modes is always negative, and this means the motion involving backward modes is stable. The decay involving the forward modes is negative at the lower value of $\Omega$ and increases with $\Omega$. The value of $\Omega$ corresponding to zero decay is called the instability threshold. For the cases without external damping and with internal and external damping, the instability threshold is $352 \mathrm{rad} / \mathrm{s}$ and $1415 \mathrm{rad} / \mathrm{s}$, respectively. It is also shown that, for the case without internal damping, the decay rate becomes a negative constant value; that is, the decay versus rotating speed curve is a horizontal line located under the $\Omega$ axis; this means that the instability threshold goes into infinity and the motion is always stable. In summary, it may be concluded that the action corresponding to external damping is stabilizing, and internal damping acts as destabilizer for the higher rotating speed.

Figure 10 shows the effect of aspect ratio on the whirl frequency (Figure 10(a)) and decay rate (Figure 10(b)). From Figure 10(b), it can be seen that the instability thresholds corresponding to $l / d=10,12$, and 15 are 50628, 35148, and $22489 \mathrm{rad} / \mathrm{s}$, respectively. Also, the whirl frequencies decrease with $l / d$ as shown in Figure 10(a). The results reveal that the whirl frequency and instability threshold are 


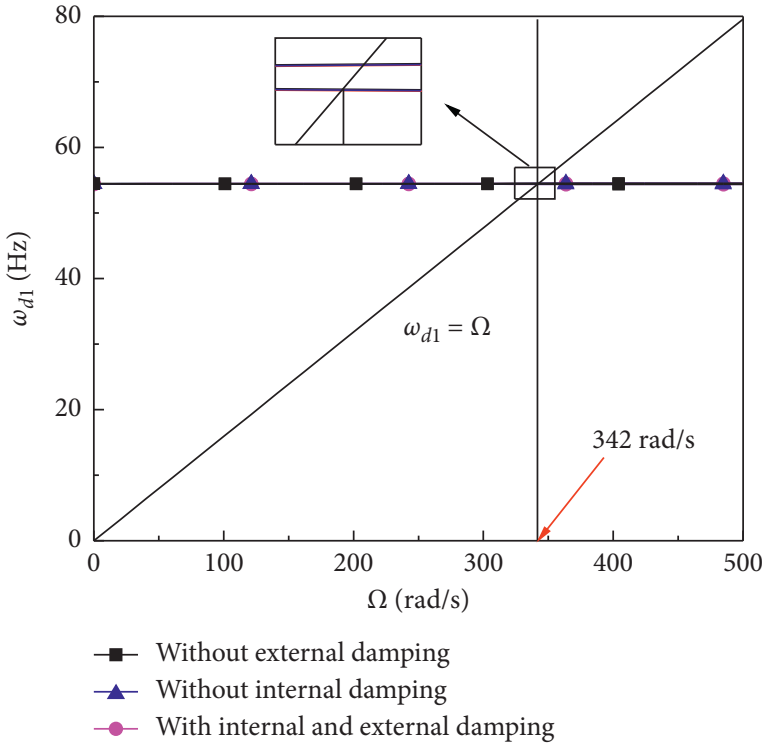

(a)

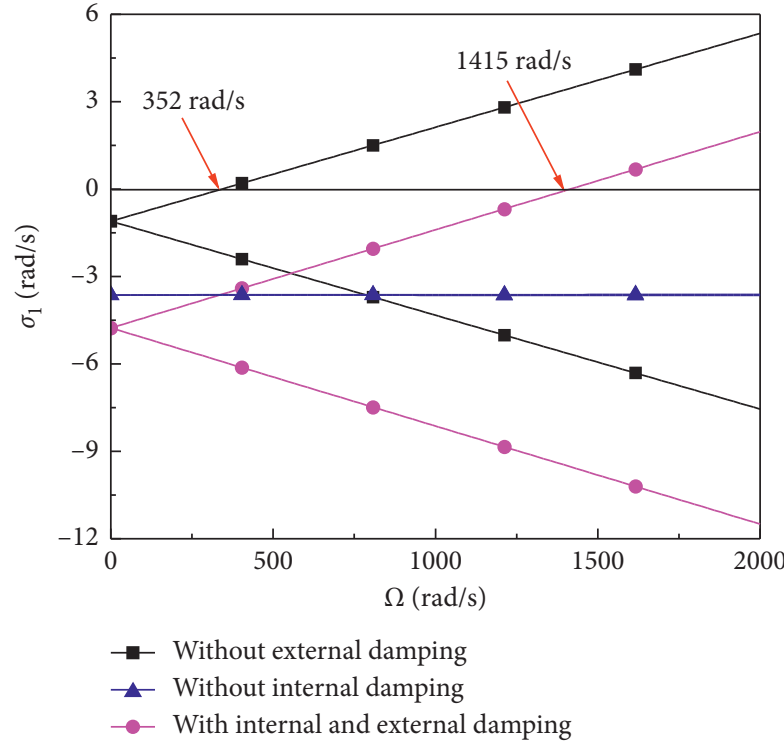

(b)

Figure 9: The effect of internal and external damping on the first whirl frequency and decay rate $\left(l / d=10, \sigma=0.5\right.$, and $\left.\theta=90^{\circ}\right)$.

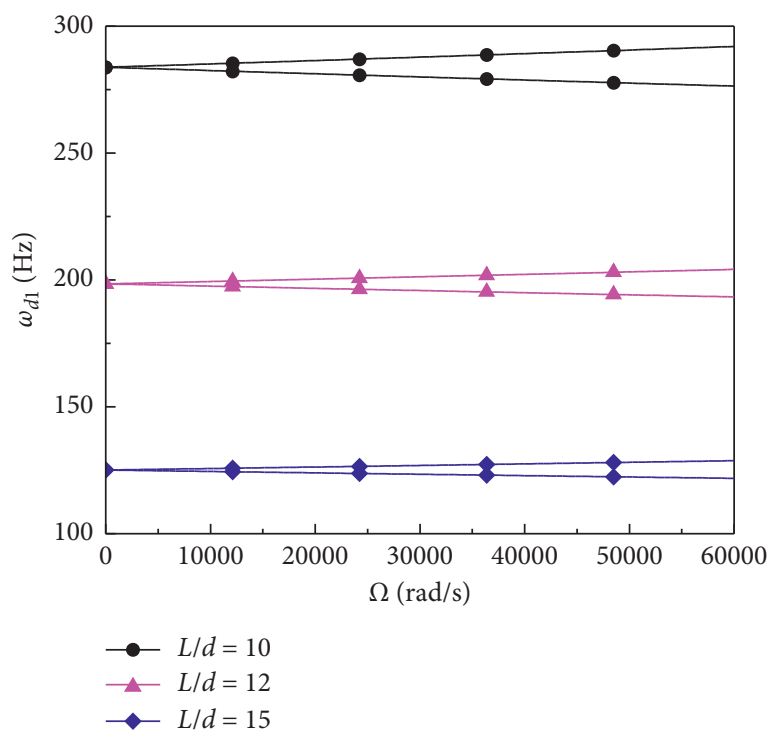

(a)

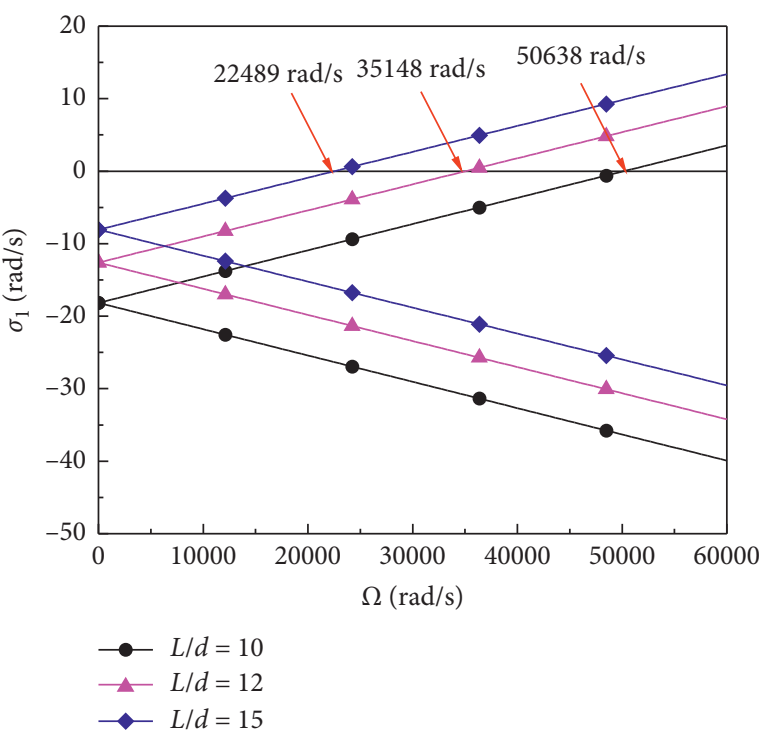

(b)

Figure 10: The effect of aspect ratio on the first whirl frequency and decay rate $\left(\varsigma=0.01, \sigma=0.75\right.$, and $\left.\theta=0^{\circ}\right)$.

inversely proportional to aspect ratio. Consequently, the slenderer the cutter bar is, the greater internal damping is and the sooner the instability occurs.

Figure 11 shows the effect of ply angle on the whirl frequency (Figure 11(a)) and decay rate (Figure 11(b)). It is clear from Figure 11(a) that the whirl frequencies increase as ply angle decreases and, consequently, the critical rotating speed increases. This is because the closer the fiber is oriented to $0^{\circ}$, the greater the cutter bar rigidity is and the higher whirl frequencies are (see Table 2).

In addition, it is evident that the instability thresholds decrease with ply angle. The reason is that the larger the ply angle is, the greater the internal damping is due to the composite materials and the more likely instability appears (see Table 2).

Figure 12 shows the effect of taper ratio on the whirl frequency (Figure 12(a)) and decay rate (Figure 12(b)). The whirl frequency and instability threshold of the tapered 


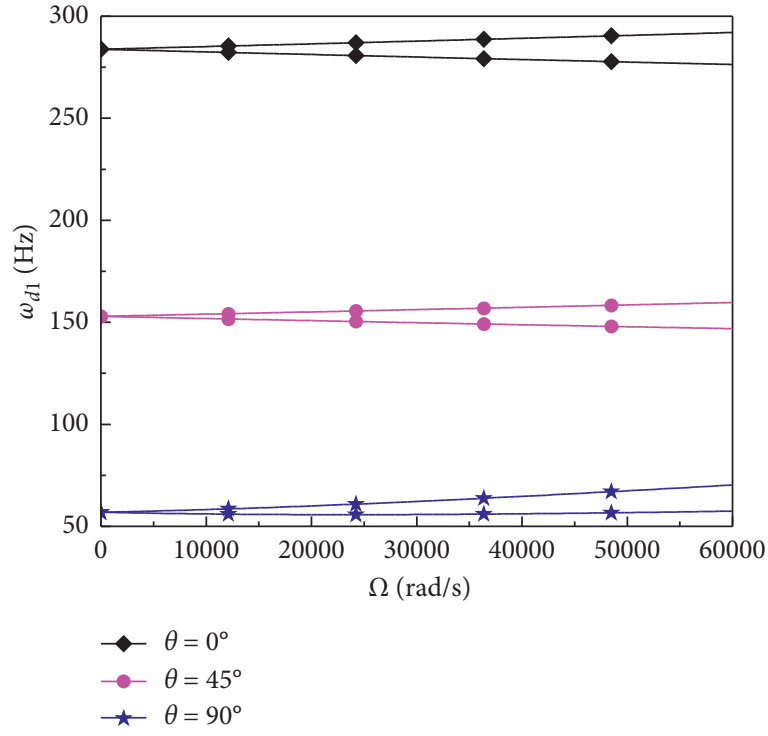

(a)

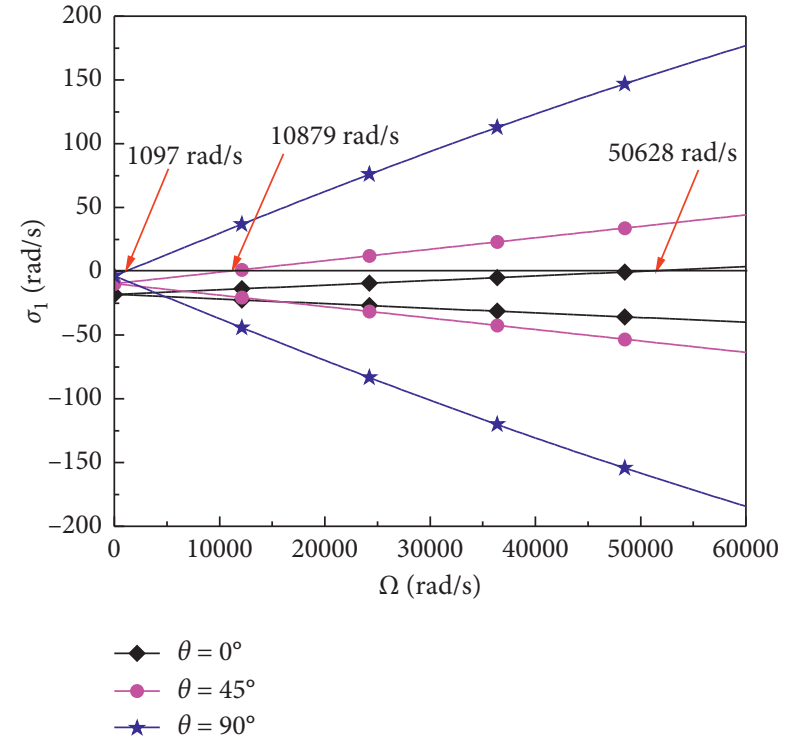

(b)

Figure 11: The effect of ply angle on the first whirl frequency and decay rate $(\varsigma=0.01, l / d=10$, and $\sigma=0.75)$.

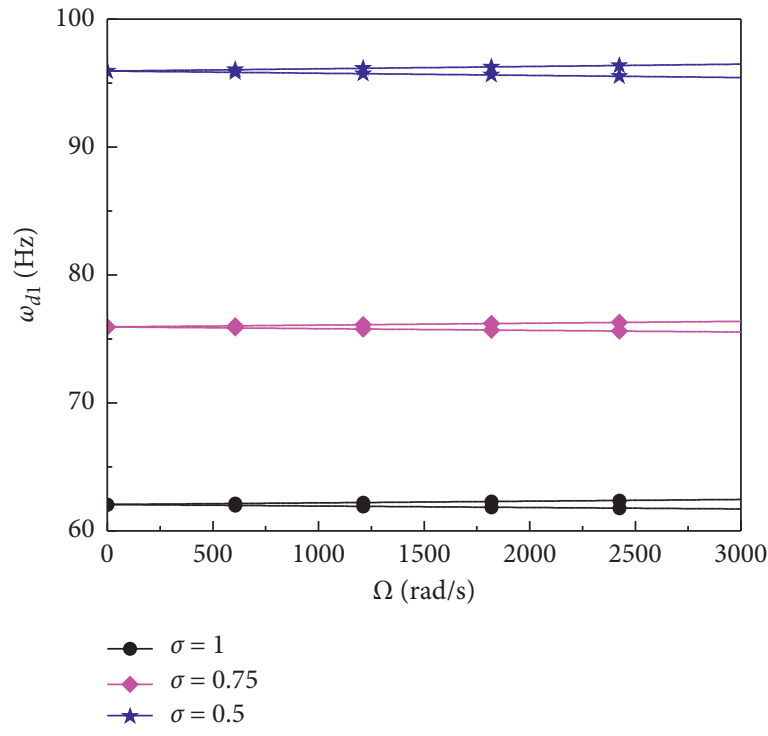

(a)

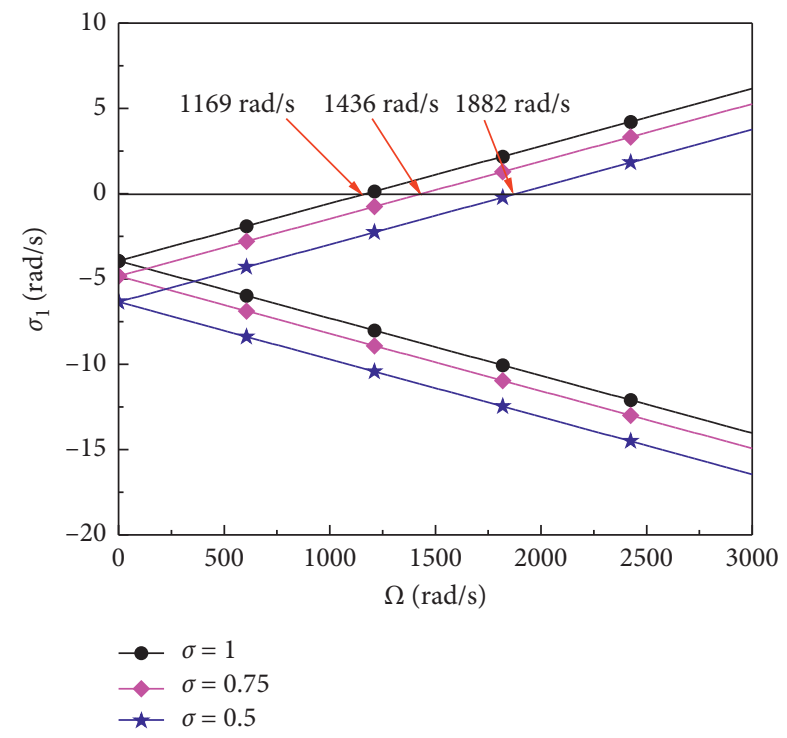

(b)

Figure 12: The effect of taper ratio on the first whirl frequency and decay rate $\left(\varsigma=0.01, l / d=10\right.$, and $\left.\theta=90^{\circ}\right)$.

composite cutter bar are larger than those of the nontapered composite cutter bar. The instability thresholds 1169, 1436, and $1882 \mathrm{rad} / \mathrm{s}$ for the nontapered $(\sigma=1)$ and tapered composite cutter bars $(\sigma=0.5$ and 0.75$)$ are shown in Figure 12(b). Moreover, the instability threshold increases as the taper ratio decreases.

Tables 8-10 summarize the effects of $l / d, \theta$, and $\sigma$ on the critical rotating speed and instability threshold. When ply angle, aspect ratio, or taper ratio increases, the critical rotating speed decreases. Instabilities occur just after the critical rotating speed.

3.4. Stability Analysis. In this section, the stability of the cutting system with a tapered rotating composite cutter bar is studied.

In the following examples, the lamination scheme, geometric and composite material properties of the cutter can be obtained from the previous section. The cutting parameters are still from [14]. 
TABLE 8: The effect of ply angle on critical rotating speed and instability threshold $(\varsigma=0.01, l / d=10$, and $\sigma=0.75$ ).

\begin{tabular}{lcc}
\hline$\theta$ & Critical speed $(\mathrm{rad} / \mathrm{s})$ & Instability threshold $(\mathrm{rad} / \mathrm{s})$ \\
\hline $0^{\circ}$ & 1809 & 50628 \\
$30^{\circ}$ & 1382 & 26225 \\
$60^{\circ}$ & 587 & 3146 \\
$90^{\circ}$ & 364 & 1097 \\
\hline
\end{tabular}

TABLE 9: The effect of aspect ratio on critical rotating speed and instability threshold $\left(\varsigma=0.01, \sigma=0.75\right.$, and $\theta=0^{\circ}$ ).

\begin{tabular}{lcc}
\hline$L / d$ & Critical speed $(\mathrm{rad} / \mathrm{s})$ & Instability threshold $(\mathrm{rad} / \mathrm{s})$ \\
\hline 12 & 1253 & 35148 \\
14 & 919 & 25823 \\
16 & 701 & 19768 \\
18 & 553 & 15617 \\
\hline
\end{tabular}

TABLE 10: The effect of taper ratio on critical rotating speed and instability threshold $\left(\varsigma=0.01, l / d=10\right.$, and $\left.\theta=90^{\circ}\right)$.

\begin{tabular}{lcr}
\hline$\sigma$ & Critical speed $(\mathrm{rad} / \mathrm{s})$ & Instability threshold $(\mathrm{rad} / \mathrm{s})$ \\
\hline 0.25 & 926 & 2773 \\
0.50 & 628 & 1882 \\
0.75 & 475 & 1436 \\
1.00 & 387 & 1169 \\
\hline
\end{tabular}

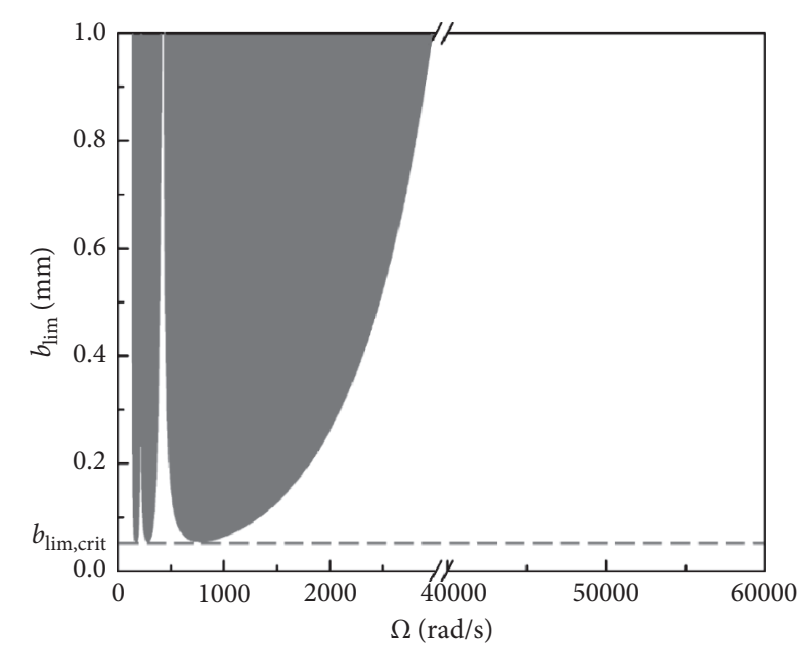

(a)

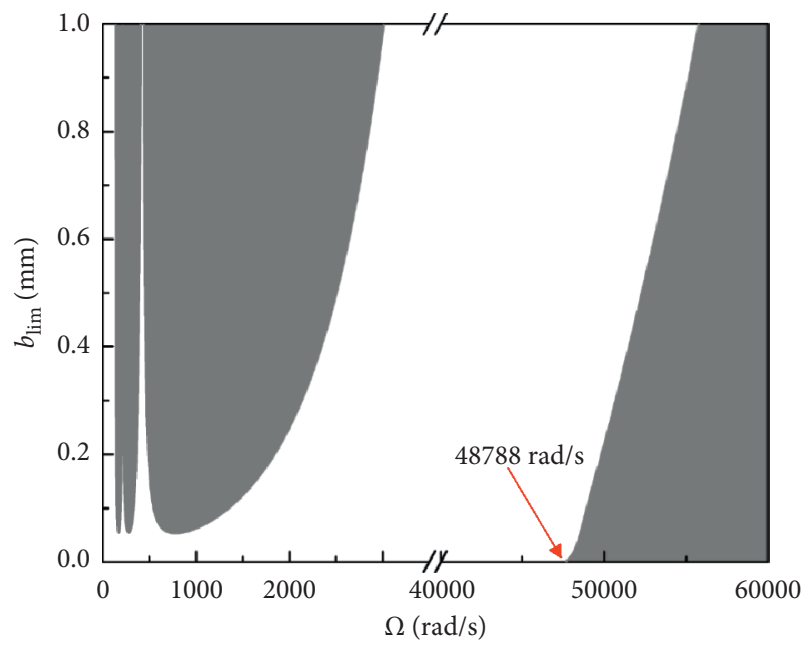

(b)

FIGURE 13: Unstable regions for milling with nonrotating and rotating composite cutter bar: (a) nonrotating bar case; (b) rotating bar case $\left(\varsigma=0.01, l / d=10, \sigma=0.5\right.$, and $\left.\theta=0^{\circ}\right)$.

3.4.1. Effect of the Rotation of Cutter Bar. This section shows how a cutter bar's rotation can influence stability of cutting process.

Figure 13 shows the unstable regions of cutting process with nonrotating and rotating cutter bar. The regions enclosed by the stability lobe diagrams, which are marked in gray, are the unstable regions, while other parts, which are marked in white, are the stable regions. Comparing Figures 13(a) and 13(b) reveals that, for the rotating cutter bar case, its unstable region is similar to the nonrotating cutter bar at lower rotating speed and a new chatter unstable region appears in high speed range due to the presence of internal damping. This can be attributed to the combined effects of internal damping, rotation of the cutter bar, and regenerative cutting fore. The unstable region starts at the rotating speed $\Omega=48788 \mathrm{rad} / \mathrm{s}$. The limit critical cutting depth of the nonrotating cutter bar is a constant, and the 


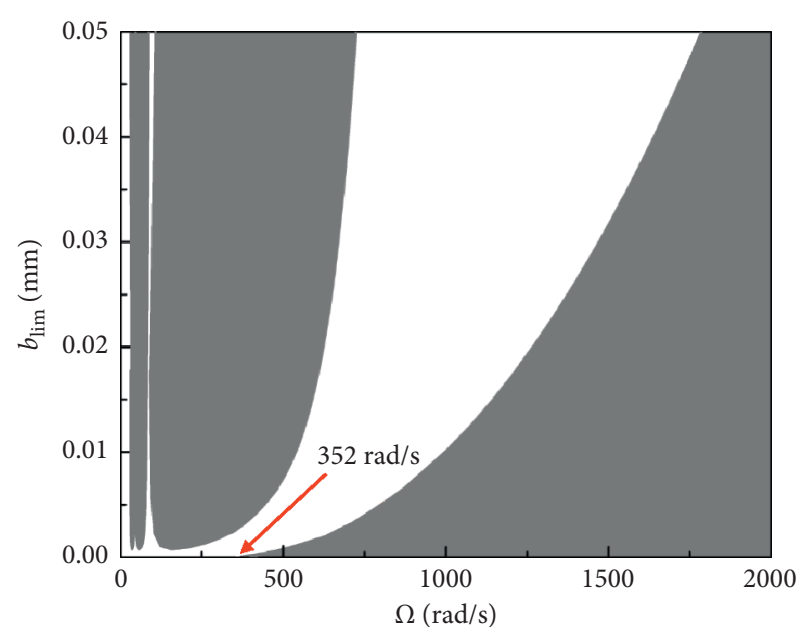

(a)

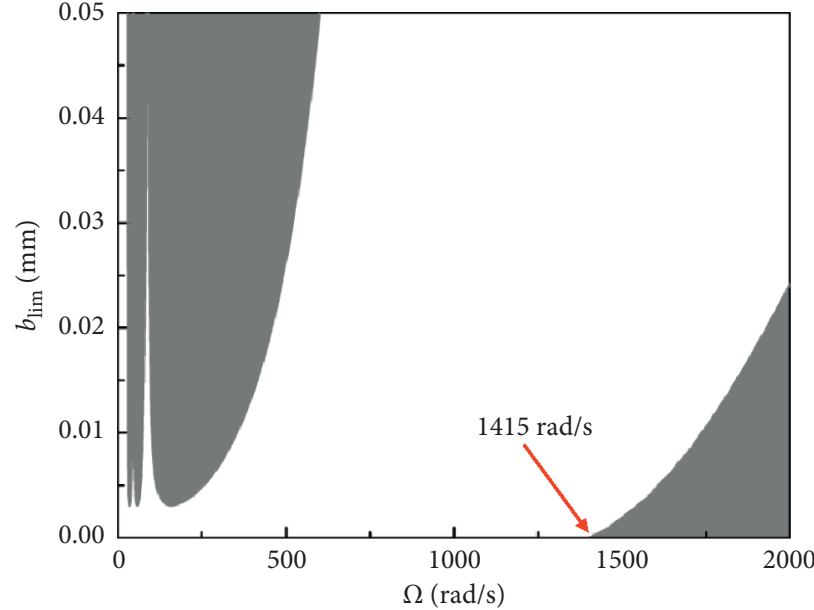

(b)

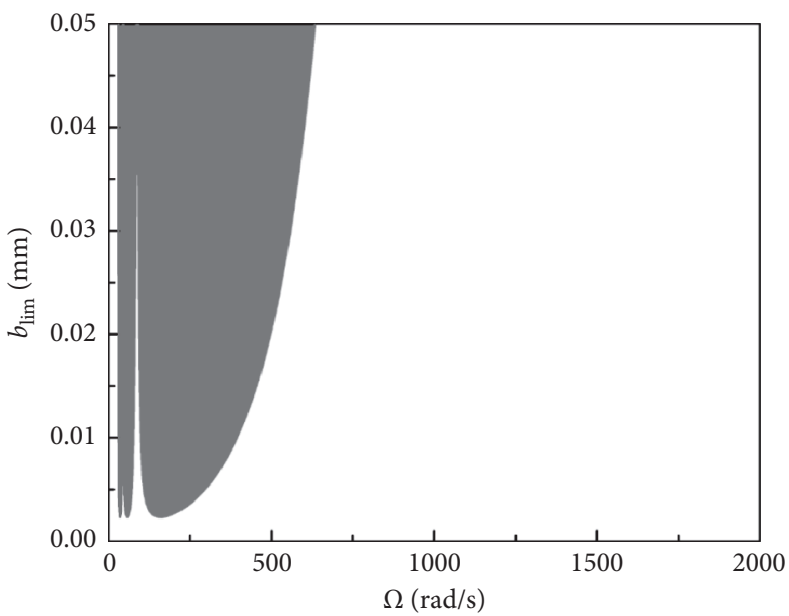

(c)

FiguRE 14: The effect of internal and external damping on unstable regions: (a) without external damping; (b) with internal and external damping; (c) without internal damping $\left(l / d=10, \sigma=0.5\right.$, and $\left.\theta=90^{\circ}\right)$.

envelope is horizontal lines. This minimum $b_{\text {lim }}$ value is referred to as the critical value, $b_{\text {lim,crit }}$ (see Figure $13(\mathrm{a})$ ).

\subsubsection{Effect of Internal Damping and External Damping.} In the following example, the influences of internal and external damping on cutting system are studied.

Figure 14 shows the effect of internal and external damping on unstable regions. Three cases, namely, without external damping (Figure 14(a)), with internal and external damping (Figure 14(b)), and without internal damping (Figure 14(c)), are considered. Only when internal damping is included, whether or not external damping exists, a new unstable region always appears at high rotating speeds; the onset rotating speed of this new unstable region is equal to the instability threshold of the rotating cutter bar. For example, as shown in Figures 14(a) and 14(b), these onset rotating speeds are 352 and $1415 \mathrm{rad} / \mathrm{s}$, respectively. These values are consistent with the critical rotating speed and instability threshold (see Figure 9). The depth of cut corresponding to the start point of unstable region becomes zero. When internal damping is ignored, no unstable region is developed at high rotating speed.

3.4.3. Effect of Aspect Ratio. In this section, the effect of aspect ratio of cutter bar on stability of cutting process is discussed.

Figure 15 shows the effect of aspect ratio on unstable regions. It can be seen that the area of new unstable region in higher speed ranges increases with aspect ratio. The new unstable starting points for different aspect ratios correspond to the instability thresholds of the rotating cutter bar in Figure 10(b). Additionally, it can also be seen that when aspect ratio increases, the stability diagrams are lowered, and consequently stable regions decrease in low speed ranges.

3.4.4. Effect of Ply Angle. Furthermore, the effect of the ply angle of the layers on cutting stability is analyzed. 


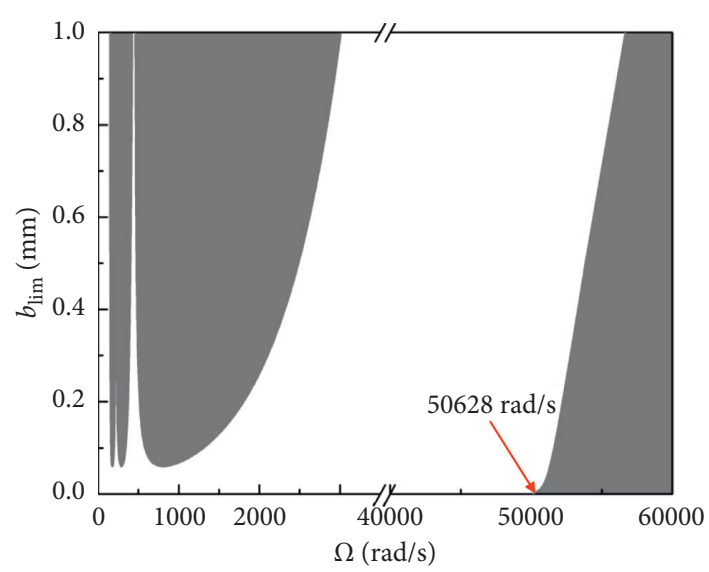

(a)

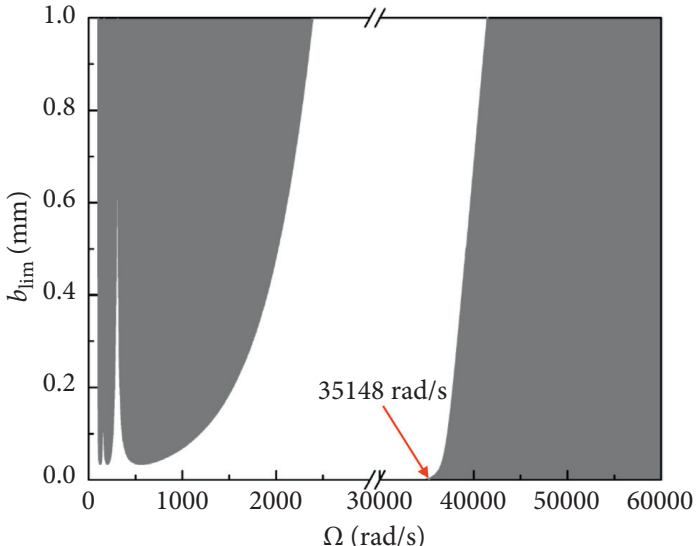

(b)

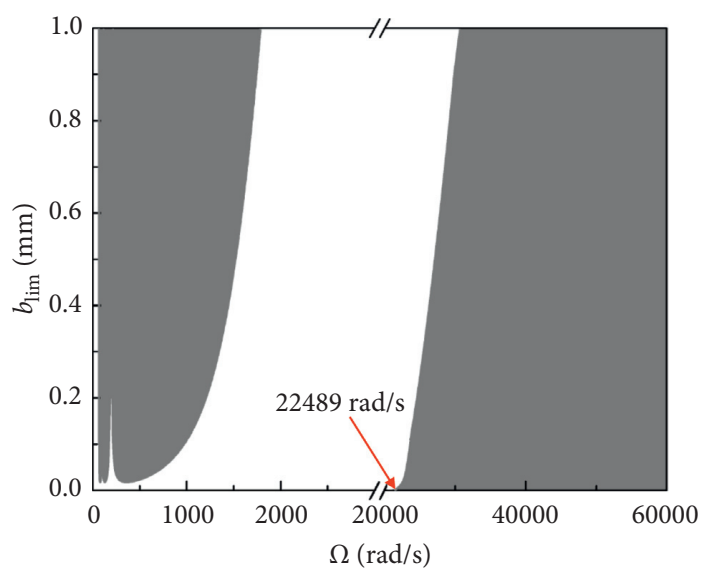

(c)

Figure 15: The effect of aspect ratio on unstable regions: (a) $L / d=10$; (b) $L / d=12$; (c) $L / d=15\left(\varsigma=0.01, \sigma=0.75\right.$, and $\theta=0^{\circ}$ ).

Figure 16 shows the effect of ply angle on unstable regions. As ply angle increases, internal damping increases and the starting point of new unstable region shifts to the left; thus cutting instability is more prone to happen in higher rotating speed ranges. The onset rotating speed of new unstable region equals the corresponding instability threshold of the rotating cutter bar (see Figure 11(b)). It can also be noted that cutting stability is reduced in lower speed ranges due to the decrease of cutter bar rigidity with ply angle.

3.4.5. Effect of Taper Ratio. Moreover, the effect of taper ratio of cutter bar on cutting stability is studied.

Figure 17 shows the effect of taper ratio on unstable regions. It is evident that the stability of system in higher rotating speed is enhanced with the help of cutter bar tapering. The onset rotating speed of new unstable region is identical to the instability threshold (see Figure 12(b)).

3.4.6. Effect of Layers Stacking Sequence. In this subsection, the influence of stacking sequence of the layers on cutting stability is investigated. In the following example, two different layup sequences are considered, namely, symmetric and asymmetric laminates.

Furthermore, the effect of the stacking sequence of the layers on the stability of the cutting process is analyzed. Figure 18 shows the stability lobe diagrams for the symmetric laminates. The symmetric laminates have six layers with two different fiber orientation angles. It is clearly understood from the results presented in Figure 18 that the greater the number of the layers that have fiber orientation of $0^{\circ}$ is, the more they contribute to cutter bar longitudinal stiffness and, consequently, the larger stable depths of cut are in low-speed region. Meanwhile, the less the number of the layers with fiber orientation of $0^{\circ}$ is, the lower the longitudinal damping is due to the composite materials and, consequently, the later a new instability occurs in high-speed region.

Figure 19 shows the stability lobe diagrams for the asymmetric laminates. The layup for the layers starts from inside, and there are ten layers with six plies at $0^{\circ}$, two plies at $90^{\circ}$, one ply at $45^{\circ}$, and one ply at $-45^{\circ}$.

The layers near the outer surface have larger circumferences and volumes than those near the inner surface of the cutter bar [22], and they withstand more the bending 


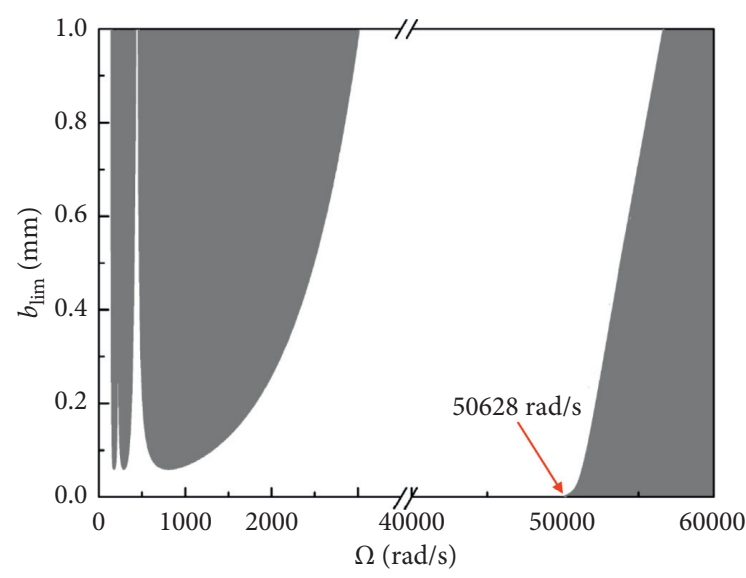

(a)

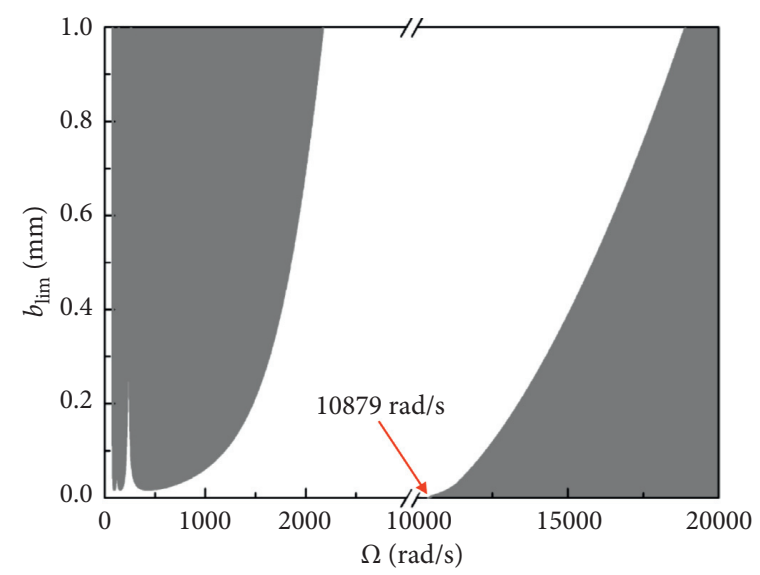

(b)

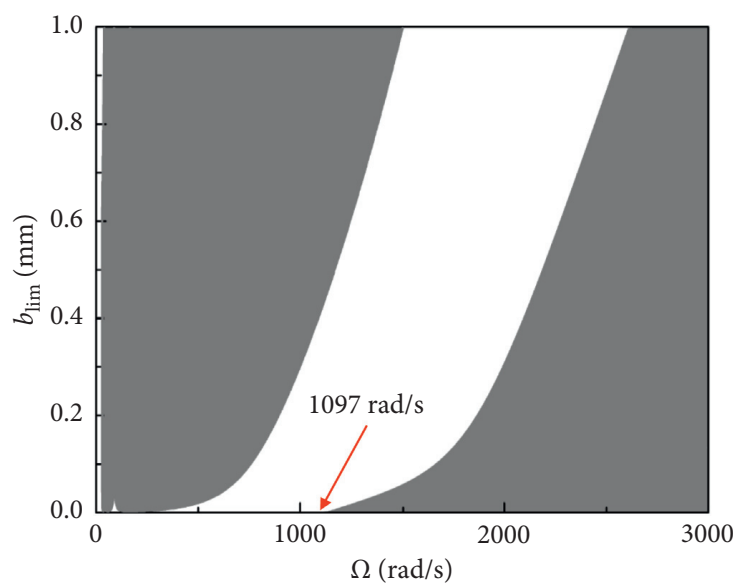

(c)

Figure 16: The effect of ply angle on unstable regions: (a) $\theta=0^{\circ}$; (b) $\theta=45^{\circ}$; (c) $\theta=90^{\circ}(\varsigma=0.01, l / d=10$, and $\sigma=0.75$ ).

moments from elastic stress and dissipative stress [12] compared to those layers which are near the inner surface of the cutter bar; as a result, the outer surface layers control the stiffness and damping of the cutter bar. The layers with fiber orientation of $0^{\circ}$ have higher stiffness and lower damping than other layers, so laying up them near the outer surface increases the stability of cutting system. Thus, the configuration $\left[90^{\circ} / 45^{\circ} /-45^{\circ} / 90^{\circ} / 0_{6}^{\circ}\right]$, where the layers with $0^{\circ}$ fiber orientation are laid-up on the outer side of the cutter bar, has better stability than the other configurations in Figure 19. In the configuration $\left[0^{\circ}{ }_{6} / 90^{\circ} / 45^{\circ} /-45^{\circ} / 90^{\circ}\right]$ the layers that have fiber orientation of $0^{\circ}$ are laid up on the inner side of the cutter bar. This configuration has the lowest longitudinal stiffness and the highest longitudinal damping, so the corresponding cutting system is most instable, as shown in Figure 19.

The onset rotating speeds of new unstable region for different symmetric laminates with variable taper ratios and aspect ratios are presented in Tables 11 and 12 .
The onset rotating speeds of new unstable region for different asymmetric laminates with variable taper ratios and aspect ratios are presented in Tables 13 and 14 .

It can be observed from Tables 11 and 12 that the difference between the onset rotating speeds of different configurations for symmetric laminates is almost kept invariable when increasing the aspect ratio or taper ratio. For example, for $L / d=12,14$, and 16, the differences in the onset rotating speeds between configurations A and C are $180 \%$, $180 \%, 181 \%$, and $181 \%$. For $\sigma=0.25,0.5,0.75$, and 1 , the differences in the onset rotating speeds between configurations $\mathrm{A}$ and $\mathrm{C}$ are $177 \%, 179 \%, 179 \%$, and $180 \%$. However, for asymmetric laminates as shown in Tables 13 and 14, when increasing the aspect ratio or taper ratio, the difference between the onset rotating speeds of configurations $A$ and $E$ is variable. But these changes seem to be irregular.

3.4.7. Comparison of the Frequency Domain with TimeDomain Solutions. In this subsection, the prediction results 


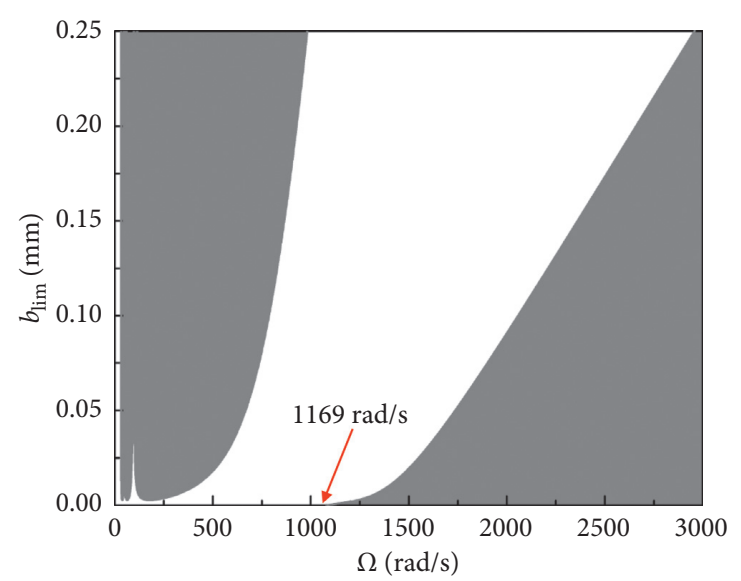

(a)

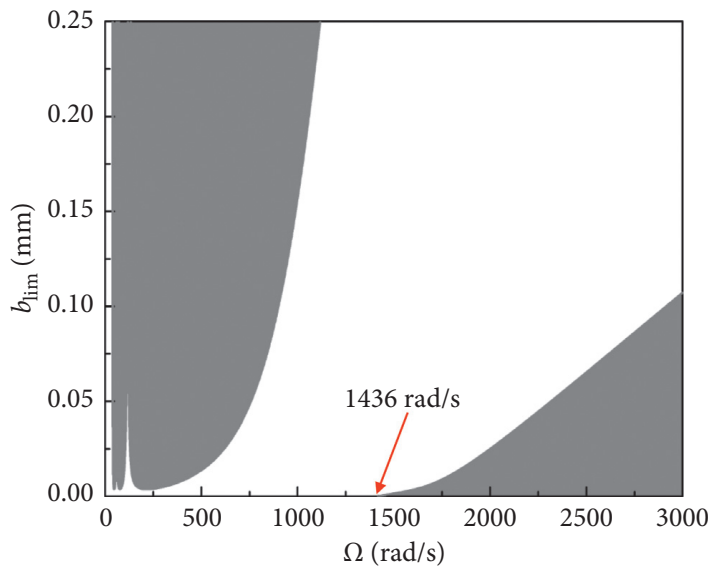

(b)

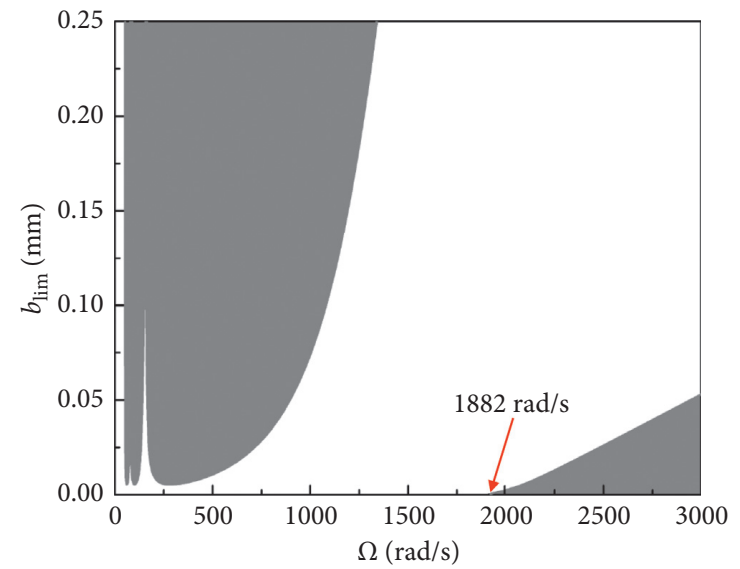

(c)

FIgURE 17: The effect of taper ratio on unstable regions: (a) $\sigma=1$; (b) $\sigma=0.75$; (c) $\sigma=0.5\left(\varsigma=0.01, l / d=10\right.$, and $\theta=90^{\circ}$ ).

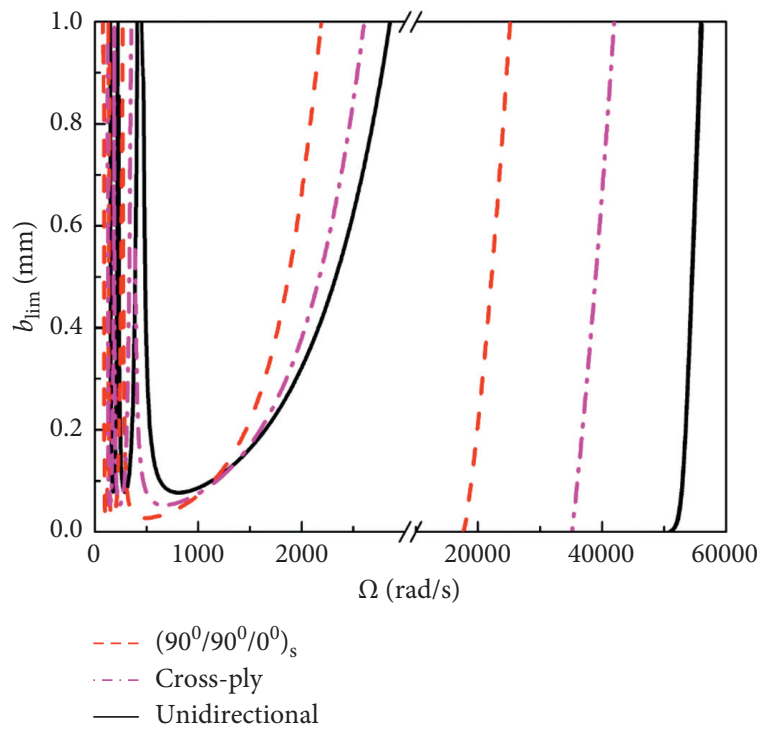

FIGURE 18: The stability lobes of the cutting process with different symmetric laminates $(\varsigma=0.01, l / d=10$, and $\sigma=0.75)$.

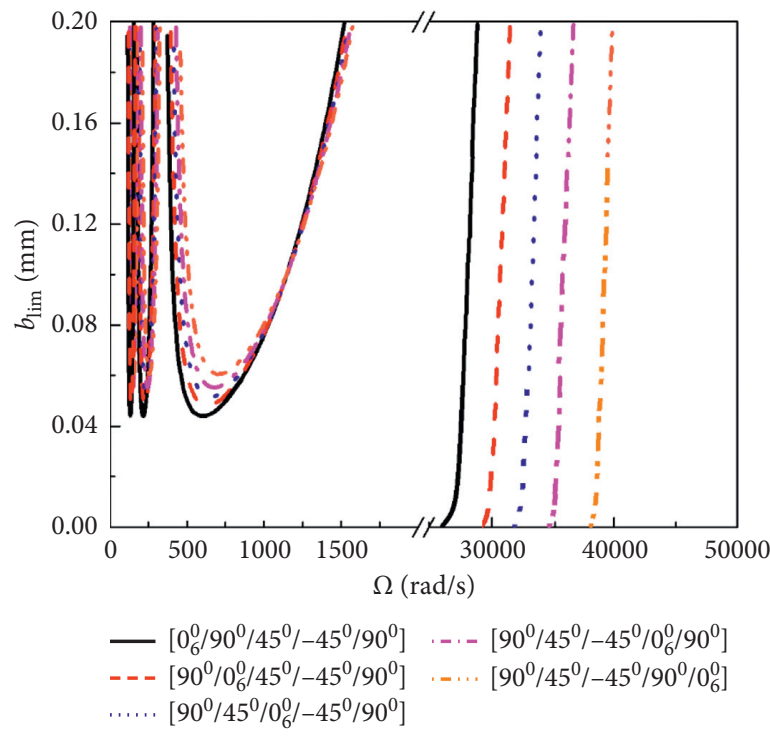

FIGURE 19: The stability lobes of the cutting process with different asymmetric laminates $(\varsigma=0.01, l / d=10$, and $\sigma=0.75)$. 
TABLE 11: The onset rotating speeds (in $\mathrm{rad} / \mathrm{s})$ of new unstable region for different symmetric laminates with variable aspect ratios $(\varsigma=0.01$ and $\sigma=0.75)$.

\begin{tabular}{|c|c|c|c|c|c|}
\hline \multirow{2}{*}{ Configuration } & \multirow{2}{*}{ Sequence } & \multicolumn{4}{|c|}{$L / d$} \\
\hline & & 12 & 14 & 16 & 18 \\
\hline A & {$\left[90^{\circ} / 90^{\circ} / 0^{\circ}\right]_{s}$} & 16298 & 12009 & 9212 & 7288 \\
\hline B & {$\left[0^{\circ} / 90^{\circ} / 0^{\circ} / 0^{\circ} / 90^{\circ} / 0^{\circ}\right]$} & 32269 & 23803 & 18272 & 14464 \\
\hline $\mathrm{C}$ & {$\left[0^{\circ}\right]_{6}$} & 45594 & 33651 & 25843 & 20464 \\
\hline
\end{tabular}

TABLE 12: The onset rotating speeds (in $\mathrm{rad} / \mathrm{s}$ ) of new unstable region for different symmetric laminates with variable taper ratios $(\varsigma=0.01$ and $l / d=10)$.

\begin{tabular}{lcccr}
\hline Configuration & Sequence & & $\sigma$ & 0.75 \\
\hline A & {$\left[90^{\circ} / 90^{\circ} / 0^{\circ}\right]_{s}$} & 0.25 & 0.5 & 17934 \\
B & {$\left[0^{\circ} / 90^{\circ} / 0^{\circ} / 0^{\circ} / 90^{\circ} / 0^{\circ}\right]$} & 39881 & 24475 & 14459 \\
C & {$\left[0^{\circ}\right]_{6}$} & 78516 & 48319 & 35495 \\
\hline
\end{tabular}

TABLE 13: The onset rotating speeds (in $\mathrm{rad} / \mathrm{s}$ ) of new unstable region for different asymmetric laminates with variable aspect ratios $(\varsigma=0.01$ and $\sigma=0.75)$.

\begin{tabular}{|c|c|c|c|c|c|}
\hline \multirow{2}{*}{ Configuration } & \multirow{2}{*}{ Sequence } & \multicolumn{4}{|c|}{$L / d$} \\
\hline & & 12 & 14 & 16 & 18 \\
\hline A & {$\left[0_{6}^{\circ} / 90^{\circ} / 45^{\circ} /-45^{\circ} / 90^{\circ}\right]$} & 25523 & 19575 & 15033 & 11904 \\
\hline B & {$\left[90^{\circ} / 0^{\circ}{ }_{6} / 45^{\circ} /-45^{\circ} / 90^{\circ}\right]$} & 28651 & 22033 & 16922 & 13400 \\
\hline $\mathrm{C}$ & {$\left[90^{\circ} / 45^{\circ} / 0^{\circ}{ }_{6} /-45^{\circ} / 90^{\circ}\right]$} & 31535 & 24311 & 18673 & 14787 \\
\hline $\mathrm{D}$ & {$\left[90^{\circ} / 45^{\circ} /-45^{\circ} / 0^{\circ}{ }_{6} / 90^{\circ}\right]$} & 33264 & 26772 & 20564 & 16286 \\
\hline $\mathrm{E}$ & {$\left[90^{\circ} / 45^{\circ} /-45^{\circ} / 90^{\circ} / 0^{\circ}{ }_{6}\right]$} & 35956 & 29892 & 22962 & 18185 \\
\hline
\end{tabular}

TABLE 14: The onset rotating speeds (in $\mathrm{rad} / \mathrm{s})$ of new unstable region for different asymmetric laminates with variable taper ratios $(\varsigma=0.01$ and $l / d=10)$.

\begin{tabular}{|c|c|c|c|c|c|}
\hline \multirow{2}{*}{ Configuration } & \multirow{2}{*}{ Sequence } & \multicolumn{4}{|c|}{$\sigma$} \\
\hline & & 0.25 & 0.5 & 0.75 & 1 \\
\hline A & {$\left[0_{6}^{\circ} / 90^{\circ} / 45^{\circ} /-45^{\circ} / 90^{\circ}\right]$} & 57945 & 38276 & 27500 & 24043 \\
\hline B & {$\left[90^{\circ} / 0^{\circ}{ }_{6} / 45^{\circ} /-45^{\circ} / 90^{\circ}\right]$} & 64733 & 42905 & 29827 & 26194 \\
\hline $\mathrm{C}$ & {$\left[90^{\circ} / 45^{\circ} / 0^{\circ}{ }_{6} /-45^{\circ} / 90^{\circ}\right]$} & 70958 & 47180 & 32898 & 29115 \\
\hline $\mathrm{D}$ & {$\left[90^{\circ} / 45^{\circ} /-45^{\circ} / 0^{\circ}{ }_{6} / 90^{\circ}\right]$} & 77564 & 51766 & 34876 & 31287 \\
\hline E & {$\left[90^{\circ} / 45^{\circ} /-45^{\circ} / 90^{\circ} / 0_{6}^{\circ}\right]$} & 85691 & 57514 & 37956 & 34352 \\
\hline
\end{tabular}

of cutting stability by the frequency domain method are compared with those by the time domain simulation.

Figure 20 shows the positions of four points in the parameter plane $\left(b_{\text {lim }} \Omega\right.$ ) (Figure $20(\mathrm{a})$ ) and the corresponding time domain response curves (Figures 20(b)$20(\mathrm{e}))$. The parameter values at these points are given in Table 15. It can be seen that the time responses related to points 2 and 4 inside the unstable regions are the chatter vibrations, while the time responses related to points 1 and 3 outside the unstable regions decrease with time. The prediction results of stability based on frequency domain solution fit well with the prediction results from time domain solution.
3.4.8. Convergence of Results. The examples of convergence study of the stability lobes are given in Figures 21 and 22 and Table 16. It is seen that the convergence of the stability lobes is good with respect to $N$, and $N=3$ are found to be adequate for convergence. So, in this section, all results have been obtained by three mode shape functions.

\section{Conclusions}

A dynamic model of the cutting process with a rotating tapered composite cutter bar is developed in this paper. Internal damping, external damping, and regenerative (delay) effects are included in the model. The internal damping of the cutter bar is modelled based on the viscoelastic constitutive equation of composite as well as an 


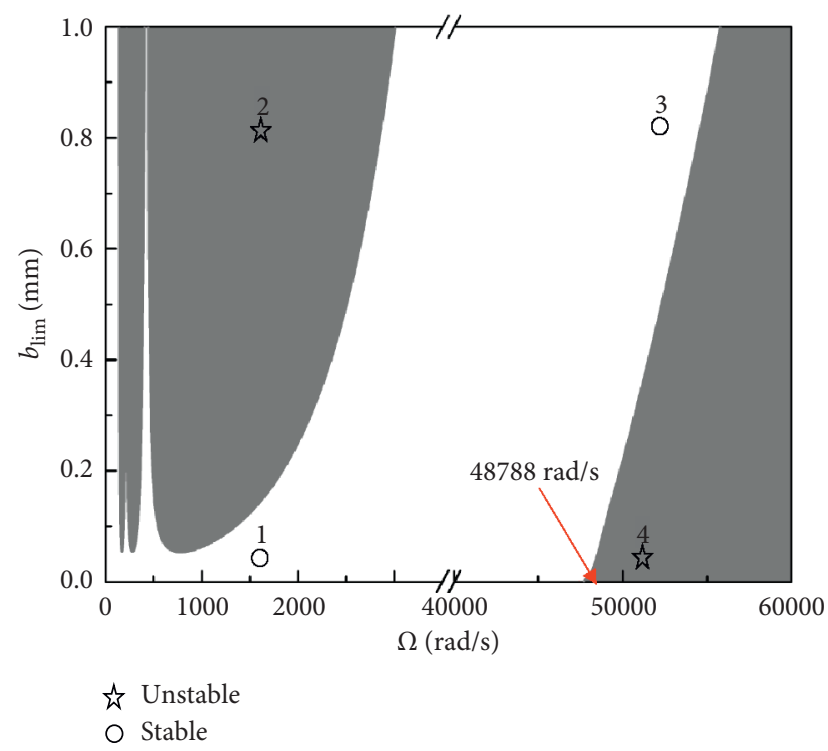

(a)
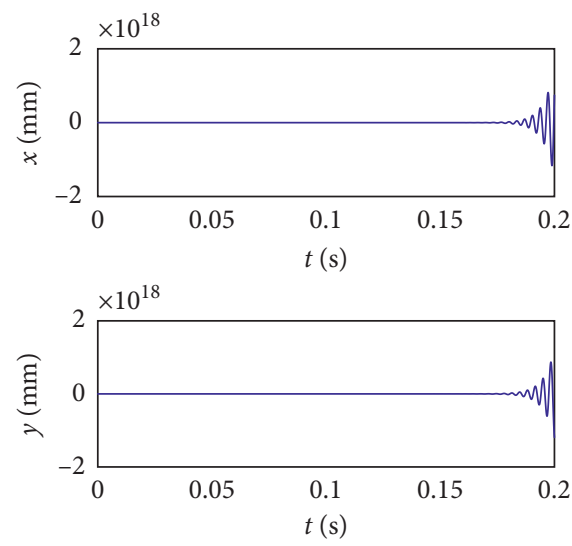

(c)
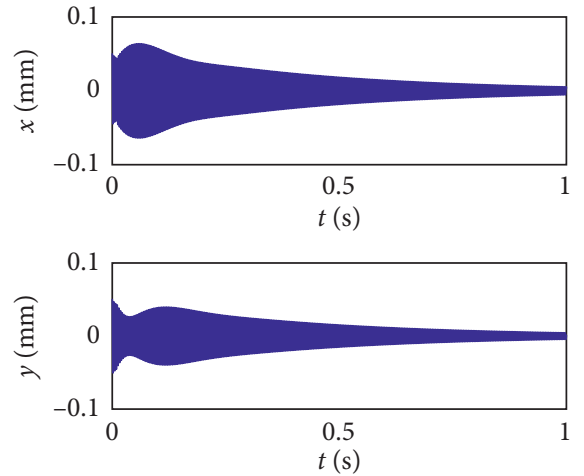

(b)
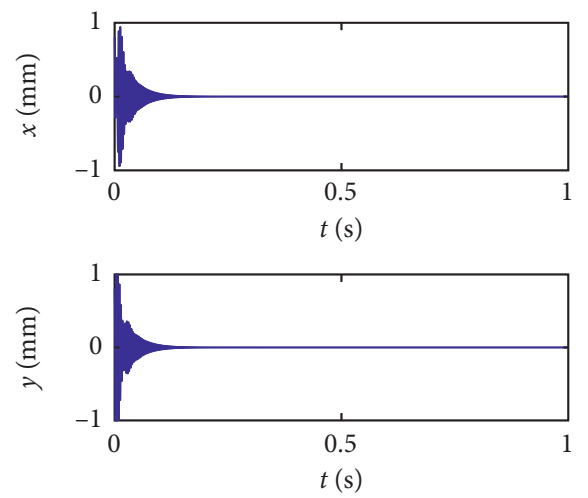

(d)
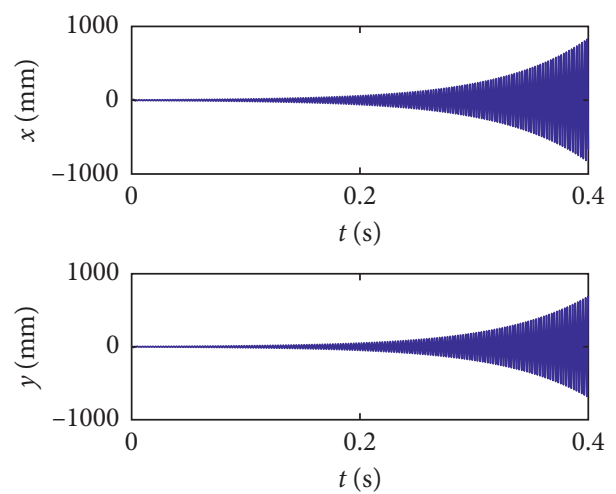

(e)

FIGURE 20: Comparison of the frequency domain with time domain solutions of cutting stability: (a) unstable region; (b) the time response of point 1 in Figure 20(a); (c) the time response of point 2 in Figure 20(a); (d) the time response of point 3 in Figure 20(a); (e) the time response of point 4 in Figure $20(\mathrm{a})\left(\varsigma=0.01, l / d=10, \sigma=0.5\right.$, and $\left.\theta=0^{\circ}\right)$.

energy approach. Taking no account of shear deformation, the equations of motion are derived with the aid of Hamilton principal and discretized by using Galerkin method. The modal loss factor, critical rotating speed, and instability threshold are determined. The frequency domain solution of stability by Altintas and Budak [14] is extended and used in the stability of the present cutting system.

The main results of this study were as follows: (1) Ply angle has a significant effect on the modal loss factor of composite cutter bar, while the aspect ratio and taper ratio 
TABle 15: Process parameters according to the points in Figure 20(a).

\begin{tabular}{lcc}
\hline No. & Rotating speed $(\mathrm{rad} / \mathrm{s})$ & Depth of cut $(\mathrm{mm})$ \\
\hline 1 & 1500 & 0.05 \\
2 & 1500 & 0.8 \\
3 & 50000 & 0.8 \\
4 & 50000 & 0.05 \\
\hline
\end{tabular}

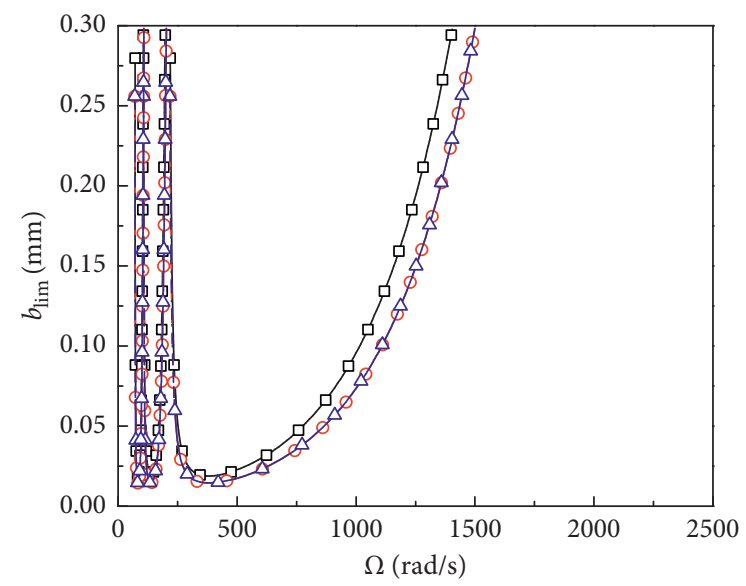

$$
\begin{aligned}
& \rightarrow-N=1 \\
& -\bigcirc-N=2 \\
& -\triangle-N=3
\end{aligned}
$$

FIGURE 21: The effect of the numbers of mode shape functions on the stability lobes (nonrotating bar, $\varsigma=0.01, l / d=10, \sigma=1$, and $\theta=45^{\circ}$ ).

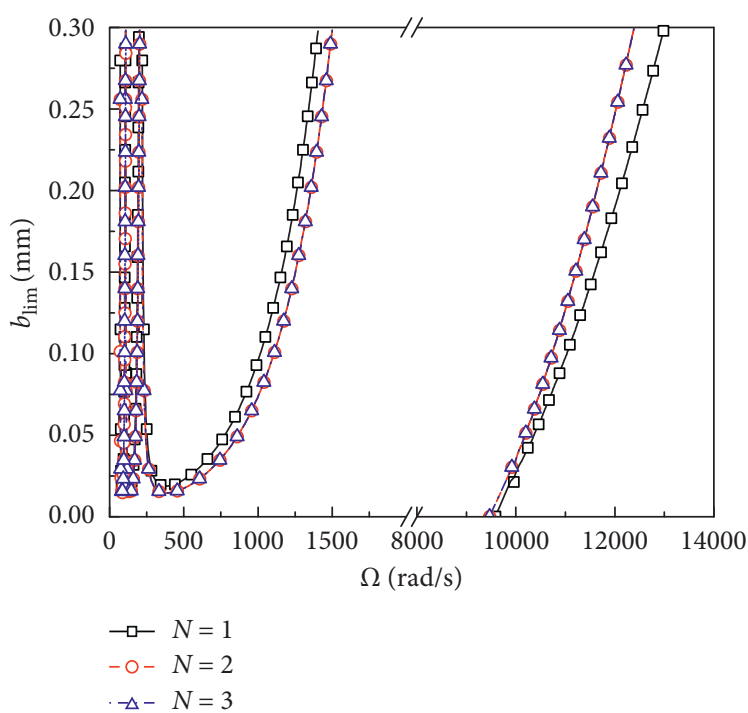

FIgURE 22: The effect of the numbers of mode shape functions on the stability lobes (rotating bar, $\varsigma=0.01, l / d=10, \sigma=1$, and $\theta=45^{\circ}$ ).

TABLE 16: The effect of the numbers of mode shape functions on $b_{\text {lim, crit }}$ (nonrotating bar, $\varsigma=0.01, l / d=10, \sigma=1$, and $\theta=45^{\circ}$ ).

\begin{tabular}{lcccc}
\hline$N$ & 1 & 2 & 3 & 4 \\
\hline$b_{\text {lim,crit }}(\mathrm{mm})$ & 0.01891 & 0.01454 & 0.01453 & 0.01453 \\
\hline
\end{tabular}

have an insignificant effect, which can be neglected. (2) Rotation and internal damping are two important factors 
affecting chatter stability of the cutting process. The effect of internal damping can be captured only if the rotation of the cutter bar is taken into consideration. (3) Chatter instability only occurs in low-speed regions, while the cutting process is stable in high-speed regions without considering rotating of cutter bar. (4) If both the rotation of the cutter bar and internal damping are taken into consideration, a new chatter instability appears in high-speed regions during the cutting process. (5) In absence of external damping, the onset rotating speed of this new unstable regions equals the critical rotating speed of the cutter bar; in presence of external damping, the rotating speed at this new chatter staring point equals the instability threshold of rotating cutter bar, which is greater than the critical rotating speed. (6) In absence of internal damping, no chatter occurs in high-speed regions during the cutting process since the instability threshold approaches infinity. (7) The rotating speed at the new chatter staring point drops with the increase of $l / d, \theta$, or $\sigma$. (8) Stacking the layers that have high longitudinal stiffness and low longitudinal damping near the outer surface of the composite cutter bar increases the stability of cutting process.

\section{Appendix}

\section{The Expressions for $\bar{Q}_{11}$ and $\bar{\eta}_{i j}$}

The formulas for calculating $\bar{Q}_{11}[15]$ are

$$
\overline{\mathrm{Q}}_{11}=C_{11} \cos ^{4} \theta+C_{22} \sin ^{4} \theta+2\left(C_{12}+2 C_{66}\right) \sin ^{2} \theta \cos ^{2} \theta \text {. }
$$

$C_{i j}$ are known functions of the layer material parameters. $\theta$ represents ply angle. $\bar{\eta}_{i j}$ can be obtained as follows:

$$
\left[\bar{\eta}_{i j}\right]=[T]^{-1}\left[\begin{array}{cccccc}
\eta_{1} & & & & \\
& \eta_{2} & & & \\
& & 0 & & & \\
& & \eta_{4} & & \\
& & & \eta_{5} & \\
& & & & \eta_{6}
\end{array}\right][T] .
$$

where $\eta_{j}$ represents damping parameters.

The transformation matrix $[T]$ can be written as

$$
[T]=\left[\begin{array}{cccccc}
\cos ^{2} \theta & \sin ^{2} \theta & 0 & 0 & 0 & 2 \cos \theta \sin \theta \\
\sin ^{2} \theta & \cos ^{2} \theta & 0 & 0 & 0 & -2 \cos \theta \sin \theta \\
0 & 0 & 1 & 0 & 0 & 0 \\
0 & 0 & 0 & \cos \theta & -\sin \theta & 0 \\
0 & 0 & 0 & \sin \theta & \cos \theta & 0 \\
-\cos \theta \sin \theta & \cos \theta \sin \theta & 0 & 0 & 0 & \cos ^{2} \theta-\sin ^{2} \theta
\end{array}\right] .
$$

\section{Data Availability}

The data used to support the findings of this study are included within the article.

\section{Conflicts of Interest}

The authors declare that they have no conflicts of interest.

\section{Acknowledgments}

This work was financially supported by the National Natural Science Foundation of China (Grant no. 11672166).

\section{References}

[1] B. B. Muhammad, M. Wan, J. Feng, and W.-H. Zhang, "Dynamic damping of machining vibration: a review," The International Journal of Advanced Manufacturing Technology, vol. 89, no. 9-12, pp. 2935-2952, 2017.

[2] J. Saffury and E. Altus, "Optimized chatter resistance of viscoelastic turning bars," Journal of Sound and Vibration, vol. 324, no. 1-2, pp. 26-39, 2009.

[3] M. Sortino, G. Totis, and F. Prosperi, "Modeling the dynamic properties of conventional and high-damping boring bars," Mechanical Systems and Signal Processing, vol. 34, no. 1-2, pp. 340-352, 2013.

[4] S. Ema and E. Marui, "Suppression of chatter vibration of boring tools using impact dampers," International Journal of Machine Tools \& Manufacture, vol. 40, pp. 1141-1156, 1999.

[5] C. V. Biju and M. S. Shunmugam, "Investigation into effect of particle impact damping (PID) on surface topography in boring operation," The International Journal of Advanced Manufacturing Technology, vol. 75, no. 5-8, pp. 1219-1231, 2014.

[6] D. G. Lee and N. P. Suh, "Manufacturing and testing of chatter free boring bars," CIRP Annals, vol. 37, no. 1, pp. 365-368, 1988.

[7] S. Nagano, T. Koizumi, T. Fujii, N. Tsujiuchi, H. Ueda, and K. Steel, "Development of a composite boring bar," Composite Structures, vol. 38, no. 1-4, pp. 531-539, 1997.

[8] Z. Yuhuan, R. Yongsheng, T. jishuang, and M. jingmin, "Chatter stability of the constrained layer damping composite boring bar in cutting process," Journal of Vibration and Control, vol. 25, no. 16, pp. 2204-2214, 2019.

[9] D. G. Lee, H. Yun Hwang, and J. Kook Kim, "Design and manufacture of a carbon fiber epoxy rotating boring bar," Composite Structures, vol. 60, no. 1, pp. 115-124, 2003.

[10] W. Kim, A. Argento, and R. A. Scott, "Forced vibration and dynamic stability of a rotating tapered composite Timoshenko shaft: bending motions in end-milling operations," Journal of Sound and Vibration, vol. 246, no. 4, pp. 583-600, 2001.

[11] J. Ma and Y. Ren, "Free vibration and chatter stability of a rotating thin-walled composite bar," Advances in Mechanical Engineering, vol. 10, no. 9, pp. 1-10, 2018.

[12] R. Sino, T. N. Baranger, E. Chatelet, and G. Jacquet, "Dynamic analysis of a rotating composite shaft," Composites Science and Technology, vol. 68, no. 2, pp. 337-345, 2008. 
[13] Y. Ren and Y. Zhang, "Investigation of chatter stability of cutting process with a rotating tapered cutter bar considering internal and external damping," The International Journal of Advanced Manufacturing Technology, vol. 107, no. 3-4, pp. 1755-1771, 2020.

[14] Y. Altintas and E. Budak, "Analytical prediction of stability lobes in milling," Annals of the CIRP, vol. 44/1, pp. 357-362, 1995.

[15] Y. Ren, Y. Shi, and Y. Zhang, "The effect of internal damping on the vibration stability of rotating composite shaft," Journal of Vibration and Shock, vol. 36, no. 24, pp. 181-200, 2017, in Chinese.

[16] E. S. Zorzi and H. D. Nelson, "Finite element simulation of rotor-bearing systems with internal damping," Journal of Engineering for Power, vol. 99, no. 1, pp. 71-76, 1977.

[17] D. A. Saravanos, D. Varelis, T. S. Plagianakos, and N. Chrysochoidis, "A shear beam finite element for the damping analysis of tubular laminated composite beams," Journal of Sound and Vibration, vol. 291, no. 3-5, pp. 802-823, 2006.

[18] I. Minis, R. Yanushevsky, A. Tembo, and R. Hocken, "Analysis of linear and nonlinear chatter in milling," CIRP Annals, vol. 39, no. 1, pp. 459-462, 1990.

[19] Y. Altintas, S. Engin, and E. Budak, "Analytical prediction of chatter stability and design for variable pitch cutters," Transactions of ASME Manufacturing and Engineering and Science, vol. 121, pp. 173-178, 1999.

[20] Y. Altintas, E. Shamoto, P. Lee, and E. Budak, "Analytical prediction of stability lobes in ball end milling," Transactions of ASME Journal of Manufacturing Science and Engineering, vol. 121, pp. 586-592, 1999.

[21] Y. Altintas, "Analytical prediction of three dimensional chatter stability in milling," JSME International Journal Series C, vol. 44, no. 3, pp. 717-723, 2001.

[22] M. Almuslmani and R. Ganesan, "Vibration of tapered composite driveshaft based on the hierarchical finite element analysis," Composite Structures, vol. 209, pp. 905-927, 2019. 